\title{
Investigating Water injection in a Single-cylinder Gasoline Spark-Ignited Engines at Fixed Speed
}

\author{
Eshan Singh*, Ponnya Hlaing, Robert W. Dibble \\ Clean Combustion Research Center, King Abdullah University of Science and Technology \\ (KAUST), Thuwal, Saudi Arabia - 23955
}

*Corresponding author: eshan.singh@kaust.edu.sa

\begin{abstract}
:
Evermore stringent emission norms have always brought forth innovative measures to improve engine efficiency. Spark-ignited engines have been limited in efficiency, traditionally by knock, and more recently by pre-ignition too. Water injection has recently gained much traction to suppress knock, thereby improving engine efficiency. Water injection is explored further in the current work. Both port and direct injection of water are investigated at a fixed engine speed of $2000 \mathrm{rpm}$ and varying engine load. The data presented in this work emphasizes that the gains from using water injection are best realized at specific injection timing (neither too early nor too late), and the effectiveness of water in suppressing knock decreases rapidly with increasing water mass injected. In general, direct water injection offers a more significant knock reduction due to better utilization of charge cooling effect than port water injection. Engine out emission confirms a reduction in NOx and $\mathrm{CO}$, while the $\mathrm{HC}$ emissions increased when using water injection. No pre-ignition events were observed at the engine load up to 27 bar. Chemical kinetics simulations confirm the role of water in suppressing reactivity in the operating conditions considered in the current study.
\end{abstract}

Keywords: Engine knock, Water injection, Pre-ignition, pollutant emissions

\section{Introduction:}

Traditionally, spark-ignited (SI) engines have been limited by knock in achieving high efficiency. More limitations to further efficiency improvements, in the form of maximum allowable turbine-inlet temperature and pre-ignition, have emerged in modern downsized engines. A potential strategy that helps with these limitations is injecting water in the engine. The high latent heat of vaporization and specific heat can cool the charge (fuel-air mixture) and delay end-gas auto-ignition, thereby avoiding knock. High engine efficiencies are expected with its application in SI engines. Apart from SI engines application, researchers have used water injection in compression ignition engines extensively in recent years [1-7]. Water injection has also been explored in novel concepts like PPC [8] and HCCI engine operation [9].

Interest in water injection in spark-ignited engines is not recent, by any measure. As an internal coolant to suppress knock, adding water to fuel is as old as internal combustion engines themselves. Clerk tried water injection to suppress violent knock as early as 1880 [10]. Hopkinson used water spray for cooling the cylinder walls of gas engines in 1913 [11]. Researchers tried water injection in aircraft engines in the early 1940s to reduce knock and improve efficiency $[12,13]$. The researchers found that an optimum injection timing occurred between -50 to -60 CAD aTDC, where the water-to-fuel ratio was 0.3 , on the mass basis. As early as 1938, researchers used water-alcohol blends to suppress knock in aircraft engines [14, 15]. Addition of alcohol allowed 'no-freeze' operation in cold conditions. Brun et al. used three spark plugs to confine the end-gas in a particular region of the cylinder and targeted water injection in the end gas to suppress knock [12]. The focus shifted from increasing power in aircraft engines to reducing emissions in vehicles in the 1960s. Interest in water injection resurfaced, with a different aim of suppressing NOx emissions. Critical studies conducted by Nicholls et al. and several others (in the 1970s) showed significant reduction in NOx and soot emissions, little change in $\mathrm{CO}$, and increased HC emissions [16-21]. In more recent times (2015 onwards), there is a growing incentive for reducing $\mathrm{CO}_{2}$ emissions while also reducing local emissions of $\mathrm{CO}, \mathrm{HC}$, and NOx. Once again, water injection is being explored to suppress knock at high load engine operations, thereby avoiding rich 
operation. Moreover, an increasing vehicles are downsized and turbocharged, and water injection reduces exhaust gas temperatures at the turbine inlet [22-27].

Water injection has been investigated as emulsion and injected separately via plenum, port, and direct injectors. Port injection offers a low cost, modular, compact, and efficient option. However, port injection requires a relatively higher water quantity to achieve similar knock suppression as with a direct injection. Due to the various benefits, several researchers have explored port injection of water in modern engines, sometimes with alcohol, to reduce the mixture freezing point for cold driving. BMW showcased a 4\% fuel-economy improvement over the NEDC cycle in its MTwin Turbo engine using port water+methanol injection [28]. Worm et al. showed a 5\% improvement in net mean effective pressure and up to $34 \%$ improvement in thermal efficiency. However, water flow rates as high as three times that of fuel flow rates were required to achieve these improvements [26]. Lanzafame used water injection in a CFR engine to raise the RON of Naphtha fuel from 70 to 93, while its MON increased from 64 to 90 . He also observed reductions in NOx and CO emissions while the $\mathrm{HC}$ emissions increased [29, 30]. Other researchers have noted similar emission measurements the past [16, 20, 29-35]. D'Adamo et al. observed fuel efficiency benefits up to $22 \%$ at 7000 rpm when using port water injection in their numerical study [22]. Researchers at Opel observed that stoichiometric operation allowed 58\% of the full load in stock engine settings while injecting water via port injector allowed up to 92\% full-load operation. $17.9 \%$ improvement in fuel consumption was also observed. The researchers predicted that the technology would be affordable enough to enter mainstream automotive by 2025 [31]. Heinrich et al. showed efficiency improvements up to $11.6 \%$ using port water injection; most of the benefits came from the reduced need for fuel enrichment [36].

Although direct injection of water is costlier than a port injection, it provides better control and optimization of injection strategy and faster response to transient operation. Injection timing is critical to the effective utilization of water in this strategy. Hunger $e$ al. showed that early injection of water was as effective as injecting via manifold as the vaporization of direct-injected water does not begin until -125 CAD aTDC. Injecting water close to TDC leads to lower charge temperature in general. However, injecting water very close to TDC leads to lower mass fraction vaporizing before spark timing, resulting in higher in-cylinder temperature. As a fraction of injected water may extract heat from the cylinder walls, the injection timing needs to be optimized to reduce wall wetting and increase water vaporization before the spark. Increasing water injection is also known to slow the flame propagation, leading to retarded combustion phasing and increased combustion duration [33]. Thewes et al. showed worse performance with reduced water injection pressure and observed a 3.5\% increase in the region of minimum BSFC when using water [37].

While experimental data on port and direct injection of water is meager, CFD studies have helped to develop understanding of water injection [38, 39]. Due to cost and space constraints, few experimental studies have been done on direct water injection. Before a successful implementation can be made commercially, the limitations to injecting water by either port or direct injection need to be assessed. There is a need to investigate which strategy provides higher efficiency improvements for the additional cost. Injection timing of water needs to be studied carefully to program the electronic control unit for maximizing the benefit of water injection. Apart from knock at high loads, which prohibits stoichiometric operation over the entire load-speed map, modern downsized engines are also limited by maximum turbine inlet temperature. Water injection reduces exhaust temperature due to the high specific heat of the water and advanced spark timing achieved due to knock suppression [40]. An alternate approach could be increasing the octane number of the fuel, which would require either further processing the fuel to add high octane compounds (e.g., aromatics) to the fuel blends or blending more bio-derived octane boosting additives (e.g., ethanol). Either solution is costly for the refiners. In this light, water injection with lower octane-rated fuels may perform similar to higher octane-rated gasoline. Moreover, with the recent introduction of emission legislation based on real-world driving cycles, stoichiometric operation at high load conditions will be a prerequisite for vehicle's emission certification. In such a scenario, water injection will be of great value as both city, and highway driving can be achieved without requiring fuel enrichment.

89 Few gaps in existing literature can be noted. Little experimental data on water injection effectiveness with varying 90 load in heavily downsized engines are available, even lesser for direct water injection. Studies varying injection 91 timings to maximize the charge cooling effect, thereby improving knock suppression, are missing. At high load 
operation, an engine is limited by pre-ignition, a stochastic combustion event leading to high peak pressures and knock intensity. The effect of water injection on pre-ignition suppression has not been studied previously. Moreover, very few existing works talk about the chemical pathways' contribution to suppressing the engine knock in spark-ignited engines. The current work fills these gaps by using a turbocharged spark-ignited engine to examine the effect of water injection. The load is increased until the engine is knock-limited, forcing a retarded spark timing. Water is injected subsequently at a fixed spark timing of -18 CAD aTDC. Water injection is tested via both port and direct injection, and varying injection timings are compared. The efficiency benefits, combustion characteristics, and engine-out emissions are analyzed. Pre-ignition limits are tested up to 27 bar IMEP and water injection in intake, compression and late exhaust stroke is showcased to suppress pre-ignition. Moreover, the experimental observations are linked with chemical kinetics calculations to isolate the physical and chemical pathways suppressing knock.

\section{Methodology}

\subsection{Experimental Engine}

The experiments were performed on an AVL Single Cylinder Research Engine at KAUST. The engine is dedicated to pre-ignition experiments, featuring a reinforced piston and cylinder head components, which can withstand high knock intensities. The combustion chamber is a pent-roof type with a four-valve cylinder head. The engine specifications are provided in Table 1.

Table 1: Engine Specifications

\begin{tabular}{|l|l|}
\hline Displaced Volume (cc) & $454 \mathrm{~cm}^{3}$ \\
\hline Stroke & $86 \mathrm{~mm}$ \\
\hline Bore & $82 \mathrm{~mm}$ \\
\hline Compression ratio & $9.7: 1$ \\
\hline Valvetrain & 4 valve DOHC \\
\hline Combustion chamber & Pent-roof \\
\hline
\end{tabular}

The engine is installed with multiple injectors, two direct injectors (DI) and two port-fuel injectors (PFI), which allows different fluids to be injected into the cylinder simultaneously. Central DI is installed with an offset to the center of the cylinder while the side DI is placed laterally. Two port-fuel injectors are installed on the air intake, upstream of the two intake valves. A piezoelectric pressure sensor (AVL GU22CK) is installed into the combustion chamber, used to record cycle-resolved in-cylinder pressure. In addition, a glow plug is fitted in the combustion chamber, which can measure time-averaged bulk gas temperature. Engine drawing is shown in figure 1. Figure 2 shows the combustion chamber and the spatial placement of in-cylinder components.

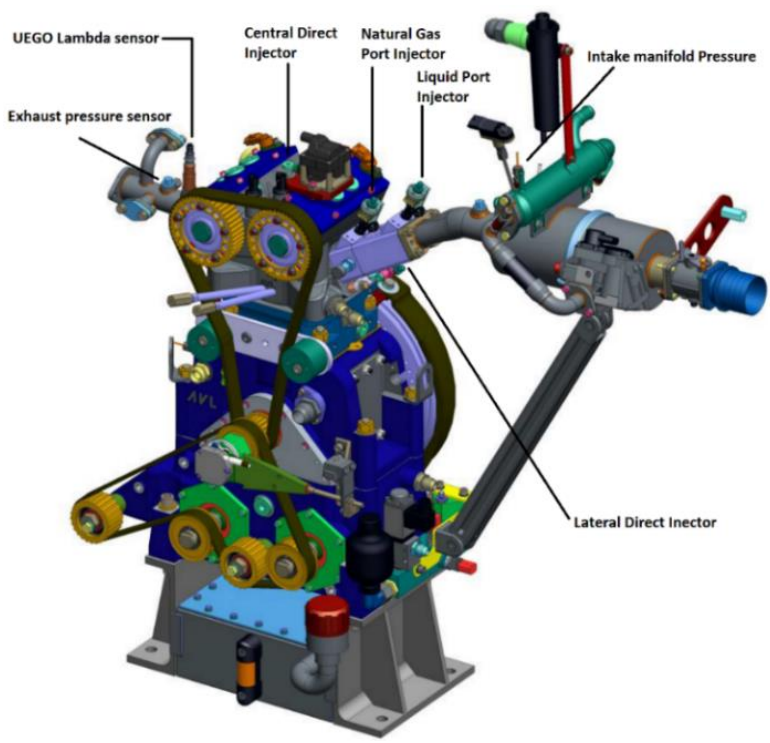

Figure 1: AVL Engine used in the current study with various injectors and sensors shown 


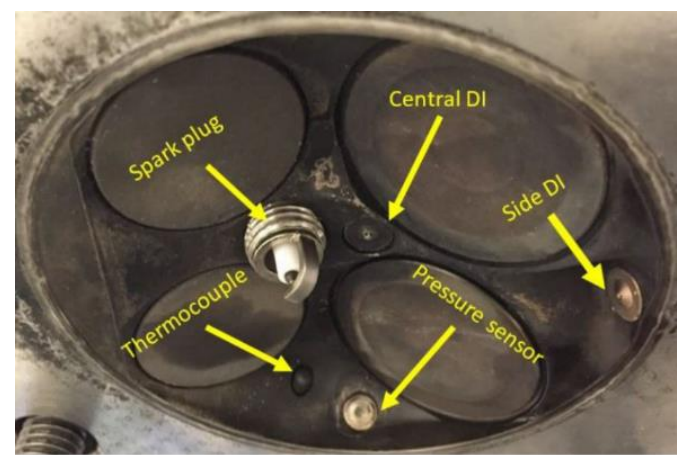

Figure 2: Relative location of injectors, sensors, and valves in the engine head

The engine control is undertaken by AVL FI ${ }^{2} \mathrm{RE}$ software, which controls start of injection (SoI), duration of injection (DoI), and spark timings (ST). The in-cylinder data such as cylinder pressure, glow plug temperature, and combustion phasing is recorded using the AVL IndiCom software. Testbed parameters, like coolant temperature $\left(80^{\circ} \mathrm{C}\right)$, lubrication oil temperature $\left(80^{\circ} \mathrm{C}\right)$, and engine speed $(2000 \mathrm{rpm})$, are controlled by the AVL PUMA control desk.

In this study, the main fuel injection was accomplished via the central DI, while the water was injected at low pressure ( 6 bar) into the air intake using the port fuel injector in the first set of experiments. The side DI was used in the second part of the study to inject water directly into the cylinder. The injection pressure for both direct injectors (fuel and water) are set at 130 bar. The results are shown in terms of variation in water mass injected. For the port injection system, injector calibration was carried out offline at varying injection durations. For the direct injection system, the flow rate is measured via a Coriolis flow meter.

\subsection{Fuel Systems}

\subsubsection{Fuel Supply System - Port Injector}

The first part of the experiments was carried out with water injection in the intake manifold. The fuel supply system for the port fuel injector is different from the central and side injector system. Instead of delivering fuel, the system is used to supply potable water to the port fuel injector. A conventional port fuel injector is employed to inject water into the air intake. The schematic of the supply system is provided in Figure 3a. The port fuel injector has four nozzles with an average diameter of $0.3 \mathrm{~mm}$. Each nozzle will produce a spray plume, and the four plumes are separated by 16 degrees. Each spray plume has a bend angle of 8 degrees. The injector is placed $130 \mathrm{~mm}$ upstream of the intake valve and was operated at 6 bar pressure.

\subsubsection{Fuel Supply System - Central Injector}

The schematic drawing of the fuel supply system for the direct injector is given in Figure 3b. A Euro V certified gasoline (RON 95) was invariably used in all the experiments (details provided later). Fuel is first pressurized with nitrogen in a fuel tank to maintain the AVL Coriolis Mass Balance System flow. The mass balance system continuously monitors fuel flow across the system, which is equivalent to the engine fuel consumption rate. Upon leaving the mass balance, the fuel is treated in the AVL Fuel Conditioning Unit, which maintains the fuel temperature steady at $20^{\circ} \mathrm{C}$. The conditioning unit also allows the venting of trapped air bubbles from the fuel system.

The fuel, thus treated by the conditioning unit, is transferred to the high-pressure fuel unit using the transfer pump installed inside the conditioner. Here, the fuel is pressurized by the high-pressure pump, which continuously feeds the common rail. An injection pressure of 130 bar is maintained in the common rail by the solenoid-operated pressure control valve, which relieves the excess pressure back into the fuel supply system. The direct injector has a six-hole configuration with a spray angle of 70 degrees and a bend angle of 15 degrees. The average diameter of a nozzle is $0.18 \mathrm{~mm}$.

\subsubsection{Fuel Supply System - Side Injector}


The fuel supply system to the side injector is identical to that of the central injector fuel system except that the mass balance system is gravimetric. However, this fuel system is used to convey potable water instead of fuel. The fuel pipelines are compatible with water application, and the high-pressure pump is, in fact, a modified version of a water pump. Thus, the system is readily available for exploring in-cylinder water injection studies.

The side injector consists of seven $0.17 \mathrm{~mm}$ diameter nozzles, placed hermetically around the nozzle tip, comprising a spray angle of 50 degrees and a bend angle of 0 degrees. The latter means that fuel is sprayed along the nozzle axis. A numerical and experimental study showed that when injecting gasoline in both injectors, the side DI has better atomization characteristics than the central DI [41]. However, owing to the difference in physical properties, water is more resistant to atomization [24].
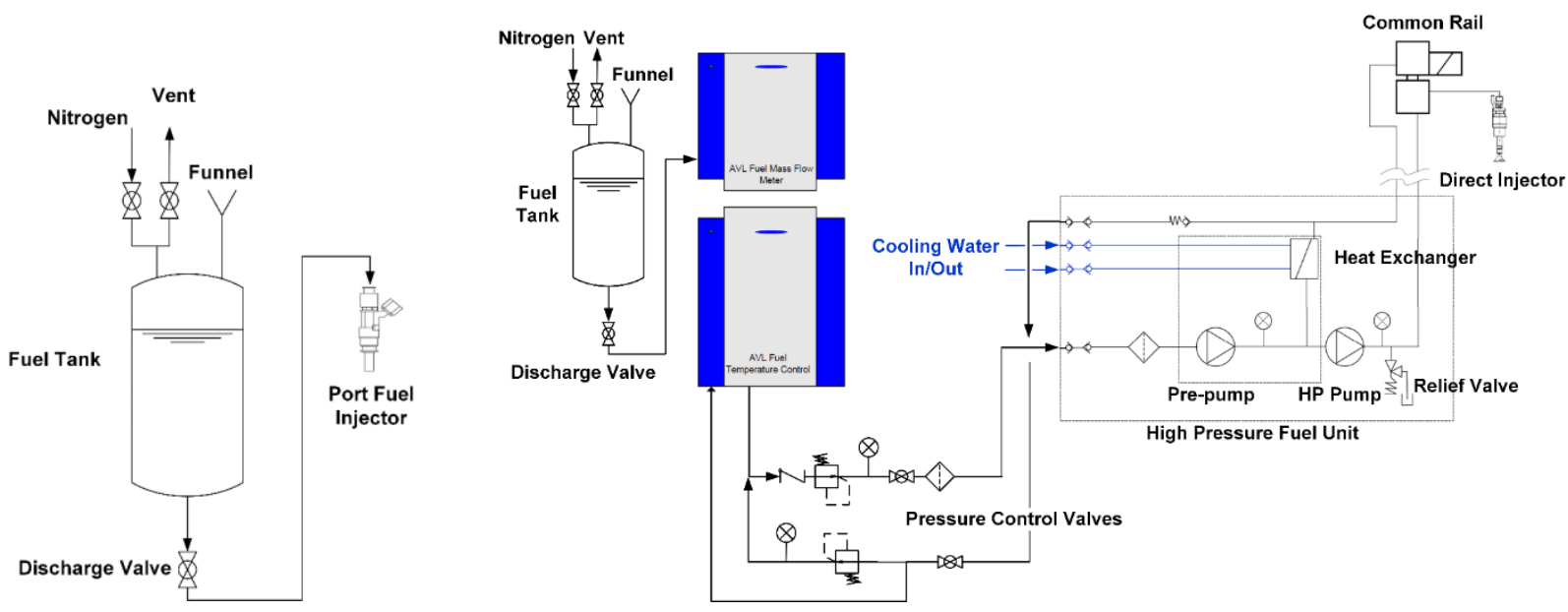

Figure 3: Fuel supply system for (a) port injector (left) and (b) direct injector (right)

\subsection{Test-cell Layout}

The layout of the engine test-cell is provided in Figure 4. The left diagram refers to the setup for water injection in the intake manifold via port injection, while the right diagram refers to the setup for water injection using the direct injector. The engine's intake air is taken from the fixed line in the KAUST engine lab via a pressure regulator. The intake air temperature is maintained at $30^{\circ} \mathrm{C}$ using an in-line air heater. A mass flow meter controls the flow rate of air to the engine and thereby controlling the air intake pressure at a steady value. Since the experimental engine is spark-ignited, a throttling valve is provided in the intake line to restrict the inlet air temperature below ambient levels. However, the current study uses wide-open throttle operating conditions only. Similarly, the exhaust backpressure valve was also kept fully opened for all data points.

\subsection{Operating Conditions}

For all the experiments, Euro V Certified Gasoline was used. The details of the fuel composition and properties are given in Table 2 and Figure 5. The engine speed was fixed at $2000 \mathrm{rpm}$ for this study. The engine coolant water and lubricating oil temperature were maintained at $80^{\circ} \mathrm{C}$. The intake air temperature was fixed at $30^{\circ} \mathrm{C}$ by the air-heater operation. The equivalence ratio $(\phi)$, as measured by the exhaust lambda sensor located $10 \mathrm{~cm}$ downstream of the exhaust valve, was kept at 1 (engine is always operated at the stoichiometric condition). In a practical scenario, maintaining a stoichiometric condition is advantageous as it would allow the usage of the three-way catalyst, which is most effective in eliminating engine-out emissions at around stoichiometry. The spark timing is varied for each operating load to achieve the maximum knock limited IMEP (KI $<0.5$ bar). A summary of a few common operating conditions can be found in Table 3. Before data acquisition, the engine is run for a minimum of 15 minutes for warmup. The warmup is ascertained by the steady value of in-cylinder thermocouple, coolant water, and lubricant oil temperature. Moreover, due to the emission sampling system's farther location in the exhaust stream, the acquisition is started once steady emission data is observed. 
The various monitoring and acquisition systems have associated uncertainty in measurements. The error in temperature measurement for the liquid fuel and water was $2^{\circ} \mathrm{C}$, while that of air, controlled via air heater, was $0.5^{\circ} \mathrm{C}$. The flow rate measurement for the direct injection system varied by $0.02 \mathrm{~kg} / \mathrm{hr}$ from the mean value, while that from the port injector has a standard deviation of $0.3 \mathrm{mg} / \mathrm{cycle}$. The pressure sensor used in the current study is AVL GU22CK, which has a maximum thermal shock error of 0.3 bar and a maximum cycle drift error of 0.6 bar. The variation in engine speed was within $2 \mathrm{rpm}$ throughout the experiments.

\subsection{Methodologies}

Two distinct research methodologies were adopted for this study, which is explained below.

\subsubsection{Water injection via port injector}

Water was injected into the air intake using the PFI, while fuel was injected through the central DI. Since the port injector operates at a low-pressure range $(\approx 6$ bar), a relatively lower water mass can be injected in each cycle. Consequently, the water injection was found to be ineffective at high load. Therefore, data were recorded at three intake air pressures: 1.07 bar, $1.22 \mathrm{bar}$, and 1.40 bar. The injection timing was chosen to achieve maximum water injection during the intake valve open time, allowing better charge cooling effects [42]. Therefore, water injection timing was kept at -270 CAD aTDC for most cases, except for two cases at intake pressure 1.40 bar, when the start of injection was moved to $-300 \mathrm{CAD}$ aTDC to allow complete injection within intake valve opening duration. The water mass injected was varied by varying the DoI. Figure 6a shows the water injection pulses overlaid on valve lift profiles. Knock limited spark-timing (KI $\sim 0.5$ bar) was used for operation without water injection and a fixed spark timing of $-18 \mathrm{CAD}$ aTDC was used for all cases with water injection.

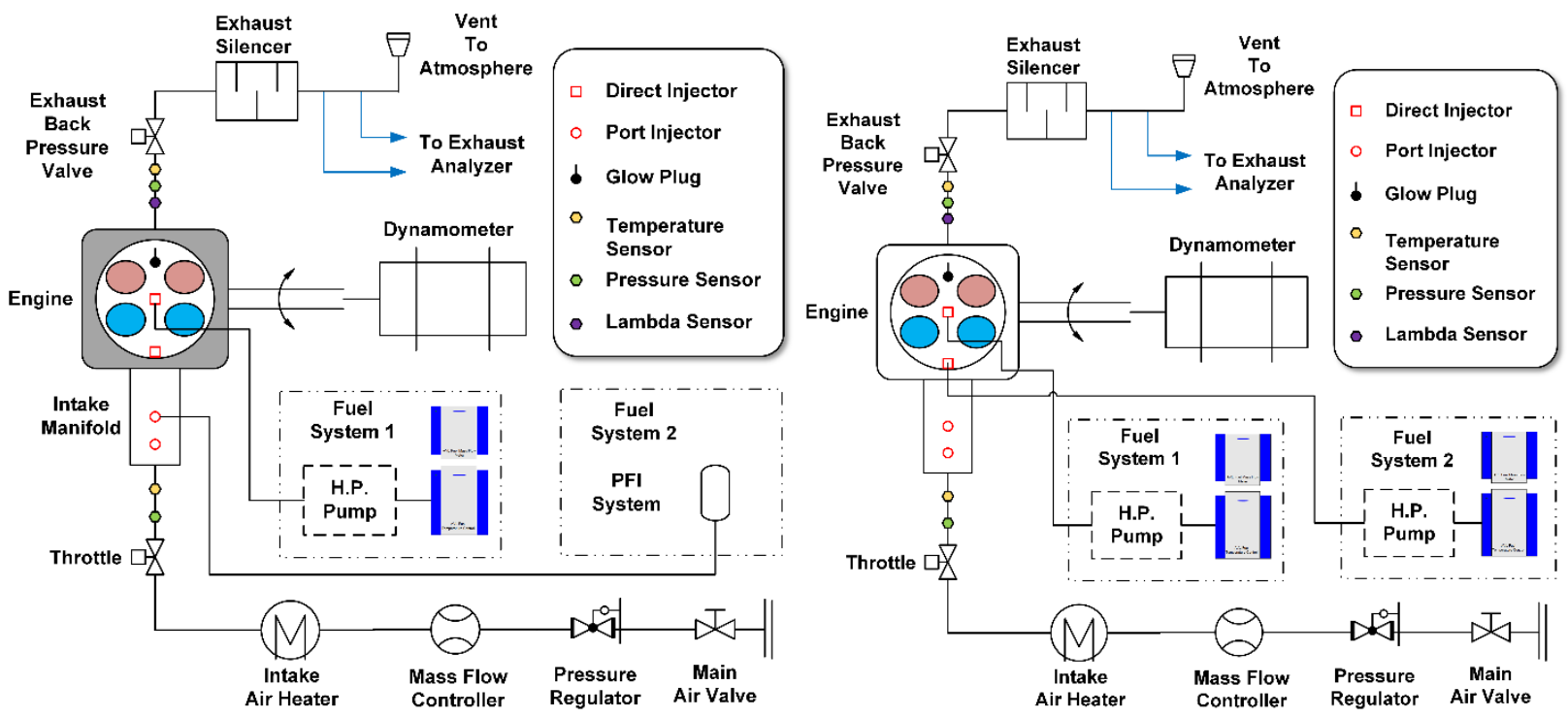

Figure 4: Test cell layout for port (left) and direct injection (right) cases studied in the current work

\subsubsection{Water injection via direct injector}

Water injection into the cylinder was achieved using the side injector, while the central injector delivered the main fuel injection. The engine is operated at various load conditions by varying the intake air pressure. Data is recorded at intake air pressure at $1.07 \mathrm{bar}, 1.22 \mathrm{bar}, 1.40 \mathrm{bar}, 1.60 \mathrm{bar}, 1.80 \mathrm{bar}$, and $2.10 \mathrm{bar}$. For each operating point, the fuel rate was adjusted to maintain the equivalence ratio of 1 , and the start of fuel injection (SoI) was kept at -300 CAD aTDC. At each load, baseline data was first recorded without water injection (i.e., the mass of water injected $=0.0$ $\mathrm{mg}$ ) at knock limited spark timing and afterward with an increasing amount of water injection and spark timing -18 CAD aTDC. The experiments were repeated at SOI of water at $-300,-200,-100$, and -50 CAD aTDC, as shown in figure $6 \mathrm{~b}$. The details of the operating points will be further addressed in the results and discussion section. 


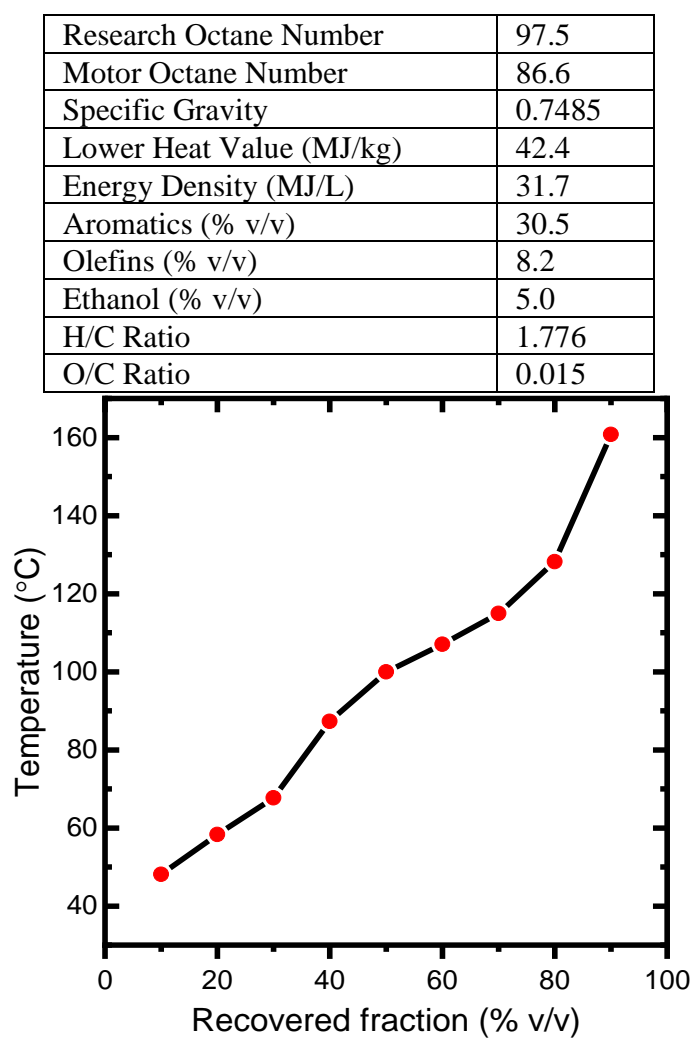

Figure 5. Measured distillation properties for Coryton Gasoline.

Table 3: Common operating conditions

\begin{tabular}{|l|l|}
\hline Engine speed & $2000 \mathrm{rpm}$ \\
\hline Intake air temperature & $30 \pm 0.5^{\circ} \mathrm{C}$ \\
\hline Cooling water temperature & $80 \pm 2{ }^{\circ} \mathrm{C}$ \\
\hline Lubricating oil temperature & $80 \pm 2{ }^{\circ} \mathrm{C}$ \\
\hline Equivalence ratio & 1 \\
\hline Spark timing & -18 (unless specified) \\
\hline
\end{tabular}

221

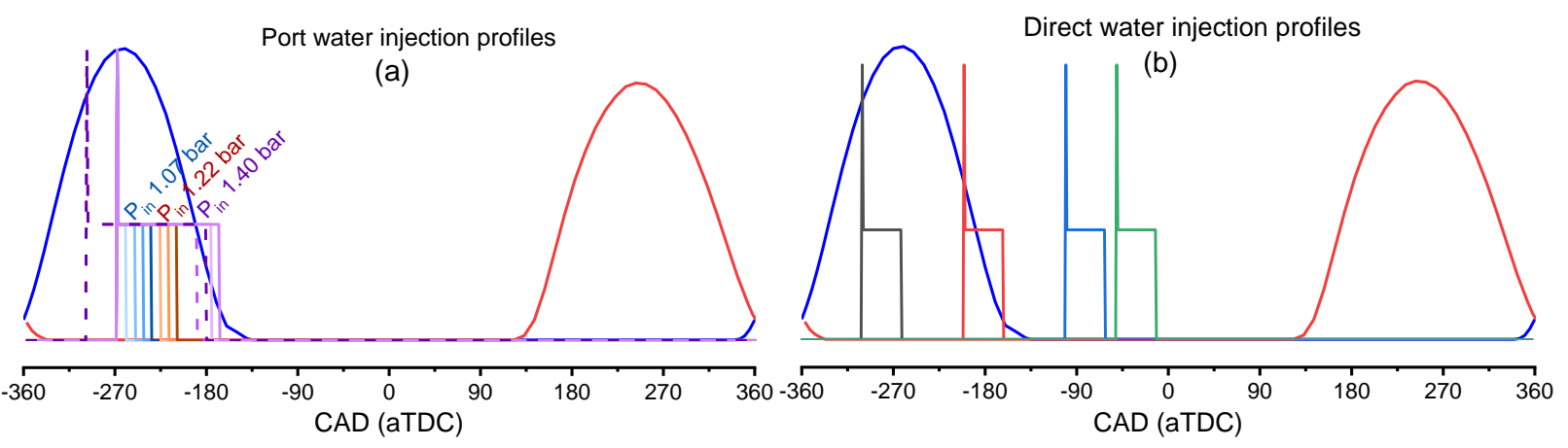

Figure 6: Injection pulses for (a) port water injector and (b) direct water injection are shown with respect to valve lift profiles of intake (blue) and exhaust (red) valves. All water injection durations are shown for port water injection case. All, except two have start of injection timing at -270 CAD aTDC. Two injection pulses at 1.40 bar intake pressure (shown by dashed lines) start at -300 CAD aTDC. Only representative injection pulses at four SoI timings used in the current work are shown for direct water injection. All injection durations are not shown for direct water injection 


\section{Results and Discussions:}

\subsection{Water injection via port injector:}

Port injection of water, often mixed with octane additives, has been used in sports cars to improve power output. In the current study, the port injection of water was attempted. The engine was operated at increasing intake air pressures. KI, IMEP indicated efficiency and indicated specific $\mathrm{CO}_{2}$ emission are plotted in figure 7 . In figure 7a, the effect of the addition of water on knock intensity is shown. The first data point of each series is representative of knock-limited operation without water injection. The spark timing was retarded to achieve tolerable knock intensity (KI 0.5 bar). The rest data points are with water injection, and spark timing advanced to -18 CAD aTDC. Naturally, knock intensity increased as the spark was advanced. With an increase in water injection quantity, the knock intensity decreases. Mass of water injection is increased until $\mathrm{KI}<0.5$ bar. The operating points with tolerable knock $(\mathrm{KI}<0.5$ bar) are shown in green. The same color convention is followed for other parameters shown in figures throughout the results and discussion section. As intake air pressure increases (increasing load) larger mass of water is required to achieve KI 0.5 bar.

Although the indicated efficiency increases for water injection cases (figure 7c), the IMEP marginally decreases for intake pressure of 1.22 and 1.40 bar (figure 7b). Advancing the spark timing results in increasing indicated efficiency. However, water injected in port displaces some of the air, leading to lower total charge burned (fuel mass was also reduced to maintain stoichiometry). At low load, a smaller mass of water increases the air density, leading to a higher mass of air inducted. However, as load increases, more water is needed to suppress knock. Most of the injected mass is not vaporized as the air is inducted. There is a compromise between an increase in IMEP from the advanced spark timing and a decrease from a lower mass of charge burnt. At lower intake air pressure, the mass of water injected is low, hence the IMEP increases. When the engine is more knock limited at higher intake air pressure, a larger mass of water is needed to reduce knock to a tolerable level. That leads to lower IMEP for higher intake air pressure values. The $\mathrm{CO}_{2}$ benefits realized from water injection via port are shown in figure $7 \mathrm{~d}$. For a given intake air pressure case, both indicated efficiency and IMEP decrease with increasing water injection. The addition of water reduces the reactivity of the mixture, from thermodynamic and chemical effect. This leads to a reduction in flame speed and combustion duration, as observed by several researchers in the past. With increasing water in the mixture, slower combustion leads to a reduction in IMEP and indicated efficiency for a given intake air pressure.

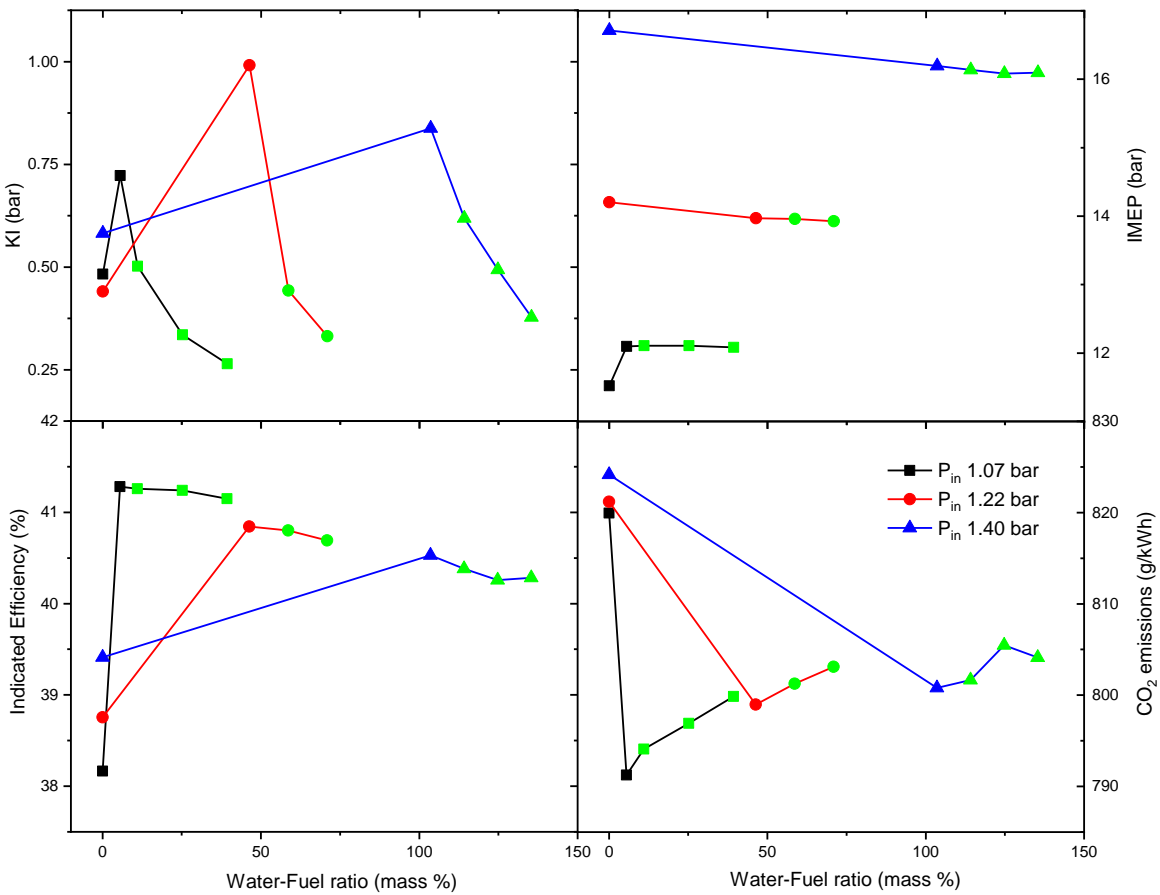


Figure 7: (a) Knock Intensity (bar), (b) IMEP (bar), (c) Indicated Efficiency (\%), and (d) $\mathrm{CO}_{2}$ emissions ( $\mathrm{g} / \mathrm{kWh}$ ) for water injection via port. Intake pressure was fixed at 1.07 bar (black), 1.22 bar (red) and 1.40 bar (blue). The baseline values refer to operation without water injection (retarded spark timing). Data-points with knock intensity (KI) less than baseline KI are marked in green.

It is widely known that water injection suppresses flame propagation, due to suppressed reactivity from lower temperatures and increased combustion duration from suppressed flame speeds. Figure 8 shows the combustion phasing for this case. For the baseline cases for each intake air pressure (no water injection), combustion phasing is retarded due to retarded knock limited spark timing. For intake air pressure 1.07 bar, combustion phasing does not change significantly initially, as this operating condition is not heavily knocked limited. As water injection increases, the mixture's lower reactivity and slower propagation leads to retarded combustion phasing.

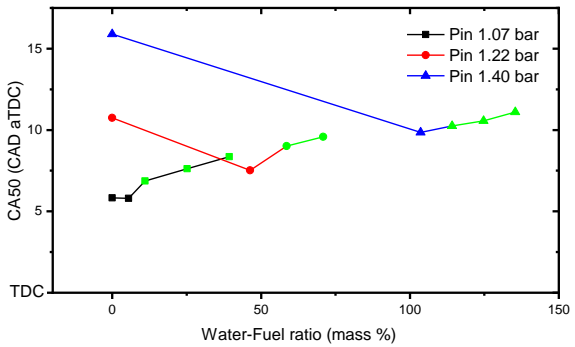

Figure 8: Combustion Phasing (CA50) for water injection via port. Intake pressure was fixed at 1.07 bar (black), 1.22 bar (red) and 1.40 bar (blue). The baseline values refer to operation without water injection (retarded spark timing). Data-points with knock intensity (KI) less than baseline KI are marked in green.

Figure 9 shows the $\mathrm{HC}, \mathrm{CO}$, and $\mathrm{NO}_{\mathrm{x}}$ emissions for this strategy. In general, $\mathrm{HC}$ emissions increase, while $\mathrm{CO}$ and $\mathrm{NO}_{\mathrm{x}}$ emissions decrease with increasing mass of water injected. $\mathrm{HC}$ emissions have been observed to increase throughout the literature. The increase of the thermal boundary layer with water injection and improper mixture formation has been attributed to these trends in $\mathrm{HC}$ emissions [20]. The complete combustion pathway undergoes $\mathrm{CO}+\mathrm{O} \rightarrow \mathrm{CO}_{2}$ reaction. Stebar et al. suggest that $\mathrm{CO}$ trends can be related to the product equilibrium conditions [20]. NOx emissions are controlled by residence time, oxygen concentration, and temperature. While not affecting the first two, water injection reduces the in-cylinder temperature, leading to lower $\mathrm{NO}$ formation. Theoretical calculations have shown to corroborate NOx reduction with water injection with high confidence [16]. Wang et al. showed that $\mathrm{OH}$ radicals (from the dissociation of water at high temperature) further suppress NOx formation [43]. The trends observed in emissions are related to reducing in-cylinder temperature due to a more significant charge cooling effect with water injection [32]. 


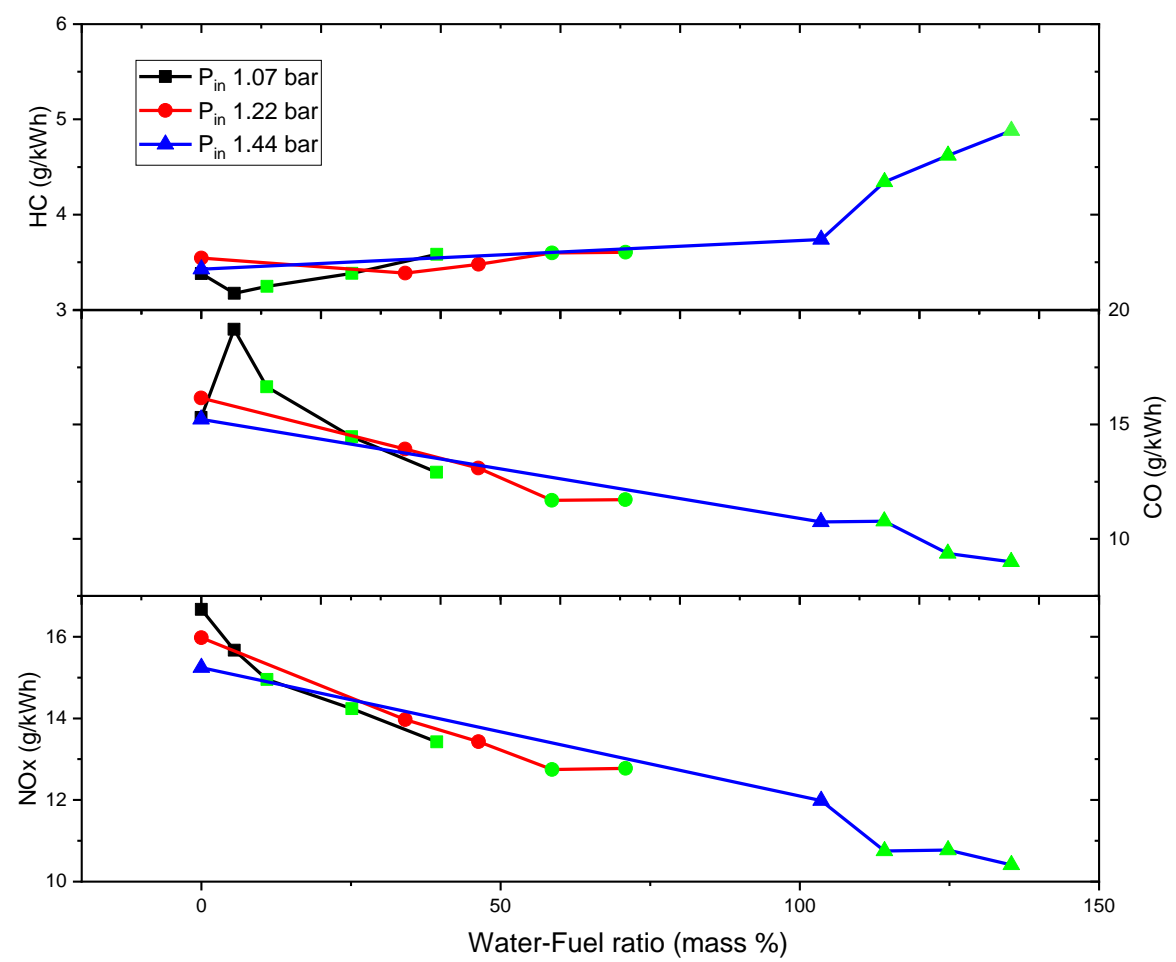

Figure 9: (a) Hydrocarbon emissions ( $\mathrm{g} / \mathrm{kWh}$ ), (b) Carbon Monoxide emissions ( $\mathrm{g} / \mathrm{kWh}$ ) and (c) Nitrogen Oxides ( $\mathrm{g} / \mathrm{kWh}$ ) for water injection via port. Intake pressure was fixed at 1.07 bar (black), 1.22 bar (red) and 1.40 bar (blue). The baseline values refer to operation without water injection (retarded spark timing). Data-points with knock intensity (KI) less than baseline KI are marked in green.

Beyond 1.44 bar intake pressure (16.5 bar IMEP), the mass of water needed is extremely high, and the injection duration is beyond intake valve opening period. This was found to be less effective at knock suppression.

\subsection{Water injection via direct injector:}

In the case of port injection of water, a large quantity of water ( $>45 \mathrm{mg} /$ cycle) was required to suppress knock at an intake air pressure of 1.44 bar. Therefore, the second set of experiments was conducted using the lateral direct injector to introduce water into the cylinder while using the central injector to supply the main fuel. Previous studies have shown better utilization of latent heat of vaporization using direct injection [26]. For each intake air pressure, the start of injection (SOI) of water was varied, while fuel injection timing is fixed at -300 CAD aTDC. Spark timing is fixed at knock-limited timing for the case without water injection and at -18 CAD aTDC when operating with water injection. The direct injection of water did not affect the mass of air being inducted in the cylinder; hence the fuel mass remained similar for a given intake air pressure condition. The observations contrast with port injection, where water injection at high loads led to lower air-fuel mass induction.

Experiments were conducted at an intake air pressure of 1.07 bar, $1.22 \mathrm{bar}, 1.40 \mathrm{bar}, 1.60 \mathrm{bar}, 1.80 \mathrm{bar}$, and $2.10 \mathrm{bar}$. At each intake air pressure, initially, baseline data is acquired without water injection (shown with 'star' symbol in the results). After that, a varying amount of water is injected at SOI of $-300,-200,-100$, and -50 CAD aTDC. Water injection at -50 CAD aTDC was not effective beyond intake air pressure 1.07 bar case. Previously, the authors have observed that injecting water very close to the top dead center may not allow the best charge cooling due to incomplete evaporation by the time of spark [44]. Representative data for only two cases: intake air pressure of $1.60 \mathrm{bar}$ and 1.80 bar are shown in the results below. The rest of the intake pressure cases are appended at the end of the manuscript.

\subsection{0 bar intake air pressure:}

Figure 10 shows knock intensity (KI), IMEP, indicated efficiency and indicated specific $\mathrm{CO}_{2}$ emissions. As seen in figure 10a, water injection effectively reduces KI value. The effectiveness decreases with further increase in mass of water injected as observed by the plateauing of knock intensity plots in figure 10a. Regarding different SOIs, retarded 
water injection timings are more effective and require lower water mass to be injected. The operating points with KI< baseline KI are shown in green. The baseline data point refers to no-water-injection and retarded spark timing of -5 CAD aTDC. IMEP 19.3 bar was achieved for the baseline case, while IMEP 20.2 bar is achieved with water injection. Efficiency gains up to $3.5 \%$ points over the baseline case were also observed. Correspondingly, $\mathrm{CO}_{2}$ emissions were reduced by as much as $60 \mathrm{~g} / \mathrm{kWh}$ for the best-case scenario.

Comparing the three injection timings, injecting water closer to TDC utilizes the charge cooling effect better. The latent heat of vaporization decreases with an increase in pressure. As the injection SoI is retarded from -300 to -100 CAD aTDC, the in-cylinder pressure at the injection time increases from 1.60 bar to 2.30 bar. An increase in pressure increases the rate of evaporation, leading to better utilization of water. Therefore, although the latent heat per unit mass decreases, water evaporates more quickly, leading to a better charge cooling effect as SOI is retarded [26]. Consequently, injection at $-300 \mathrm{CAD}$ aTDC requires excessive water mass to have tolerable knock intensity. Such large water mass slows the combustion process, leading to lower IMEP and indicated efficiency than the baseline case. The lower mass of water is required to suppress knock when injecting at -200 and even lower at -100 CAD aTDC.

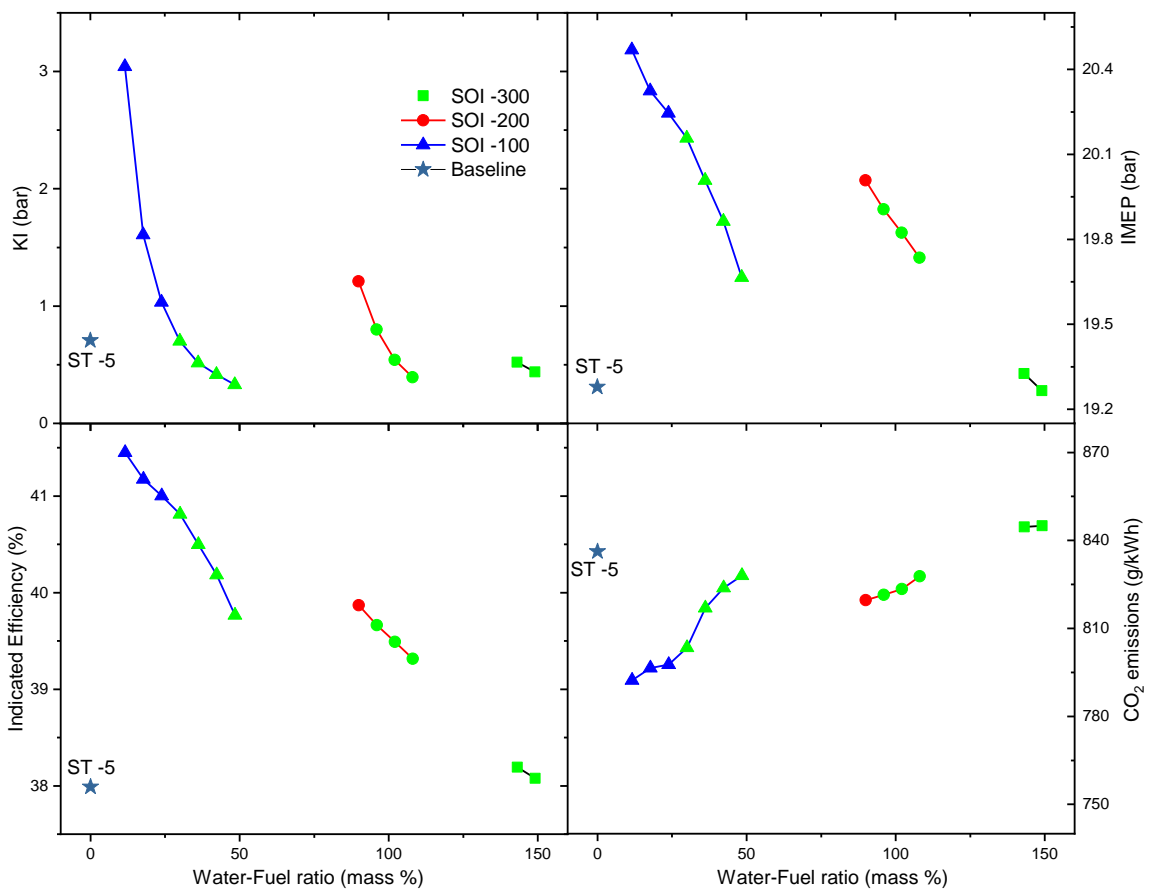

Figure 10: Knock Intensity (bar), IMEP (bar), Indicated Efficiency (\%) and $\mathrm{CO}_{2}$ emissions ( $\mathrm{g} / \mathrm{kWh}$ ) for in-cylinder water injection. Intake pressure was fixed at 1.60 bar. Four different start of injection are shown: -300 (black), -200 (red) and -100 (blue) CAD aTDC. The baseline values refer to operation without water injection (spark timing -5 CAD aTDC). Data-points with knock intensity (KI) less than baseline KI are marked in green.

Injecting water negatively affects flame propagation, as observed by several researchers in the past [21, 25, 45]. Combustion phasing is shown in Figure 11. Compared with the baseline operation, all water injection cases have an advanced combustion phasing due to advanced spark timing. For the same spark timing (all cases with water injection), combustion phasing retards with increasing water injection quantity.

Emission data is shown in figure 12. Emissions of $\mathrm{HC}$ increase while those of $\mathrm{CO}$ and NOx decrease with an increase of water mass injected. Focusing on the best SOI case of -100 CAD aTDC, HC emissions range from slightly lower for highly knocking cases to higher than baseline case for tolerable knocking cases. A knocking cycle often disturbs the thermal boundary layer, while increasing water injection increases the thermal boundary, which may explain the observed trend. $\mathrm{CO}$ and NOx emissions are lower than the baseline case for non-knocking case of SOI -100 CAD aTDC. 


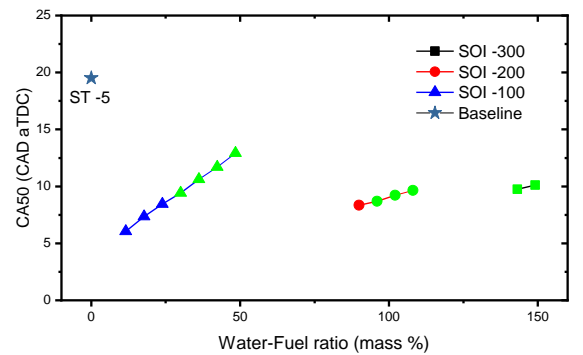

Figure 11: Combustion Phasing (CA50) is shown for in-cylinder water injection. Intake pressure was fixed at 1.60 bar. Four different start of injection are shown: -300 (black), -200 (red) and -100 (blue) CAD aTDC. The baseline values refer to operation without water injection (spark timing -5 CAD aTDC). Data-points with knock intensity (KI) less than baseline KI are marked in green.

\subsection{0 intake air pressure:}

Observations made at an intake air pressure of 1.80 bar are shown in figure 13. KI decreases tremendously with water addition. Expectedly, a relatively larger water mass is needed to achieve tolerable knock intensity for this case compared to intake air pressure 1.60 bar. Like the previous case, retarded injection timing requires lesser water mass to achieve similar knock intensity (SoI $-100<$ SoI $-200<$ SoI -300 CAD aTDC). The mass of water required to suppress knock at SoI -300 CAD aTDC is nearly 1.5 times the fuel mass. Such huge water mass slows down the combustion to the extent that the indicated efficiency is lower than the baseline case. This leads to a net increase in $\mathrm{CO}_{2}$ emissions for SoI -300 CAD aTDC, compared to the other two injection timings. Spark timing for the baseline case -3 CAD aTDC yielded IMEP 21.5 bar. For the best case of SOI -100 CAD aTDC, IMEP 22.6 bar was achieved at an indicated efficiency of $40.5 \%$ at water mass equal to $40 \%$ of the fuel mass injected.

Figure 14 shows the emissions (per $\mathrm{kWh}$ ) for intake air pressure 1.80 bar case. Like the previous case, $\mathrm{HC}$ emissions increase, while $\mathrm{CO}$ and $\mathrm{NO}_{\mathrm{x}}$ emissions decrease with water injection. $\mathrm{NO}_{\mathrm{x}}$ emissions are high for high knock intensity cases due to high peak in-cylinder temperature arising from a knock but decrease below the baseline value for low knock intensity case. For the best-case scenario of SOI -100 CAD aTDC, HC emission almost doubled, CO emissions reduced to one-third of the baseline value, while NOx emissions decreased slightly.

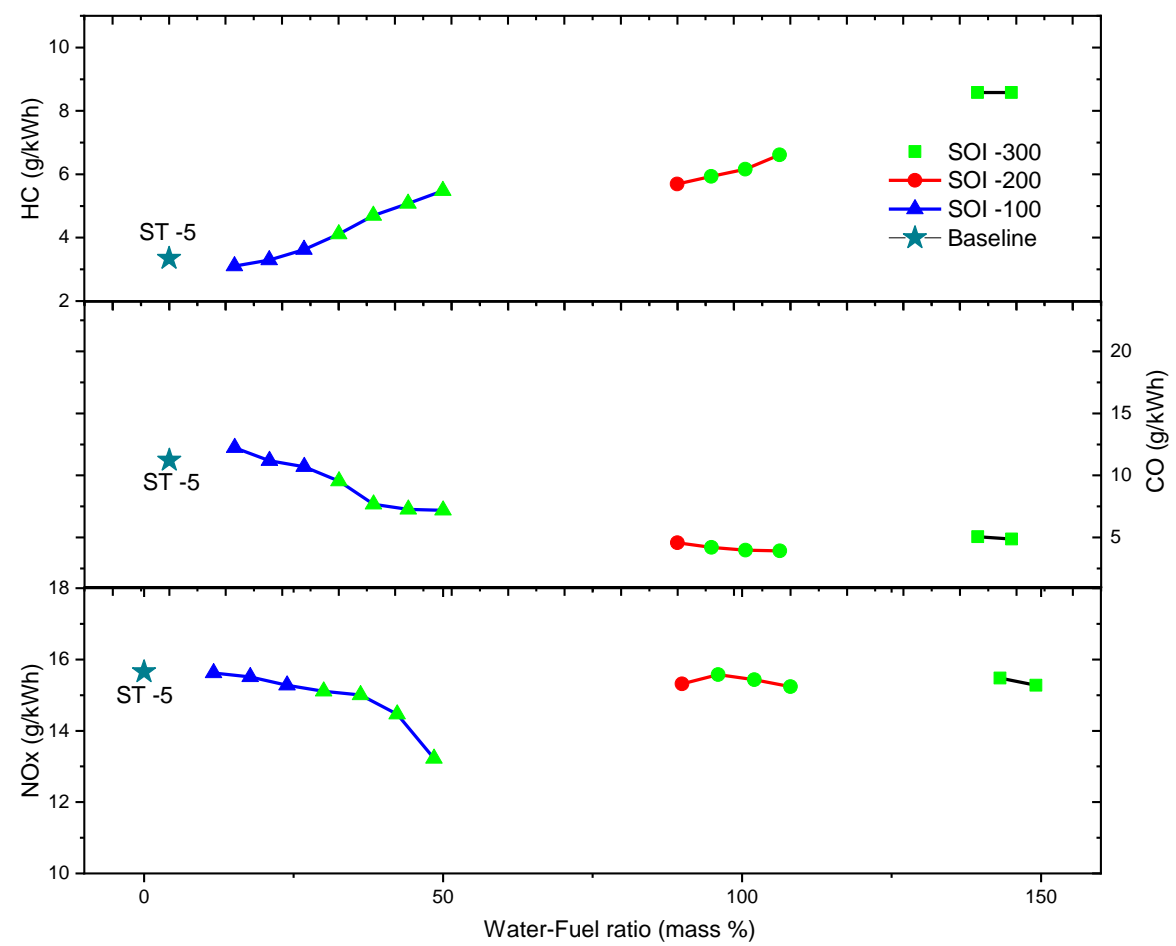


Figure 12: (a) Hydrocarbon emissions ( $\mathrm{g} / \mathrm{kWh}),(\mathrm{b})$ Carbon Monoxide emissions ( $\mathrm{g} / \mathrm{kWh}$ ) and (c) Nitrogen Oxides ( $\mathrm{g} / \mathrm{kWh}$ ) for in-cylinder water injection. Intake pressure was fixed at 1.60 bar. Four different start of injection are shown: -300 (black), -200 (red) and -100 (blue) CAD aTDC.

The baseline values refer to operation without water injection (spark timing -5 CAD aTDC). Data-points with knock intensity (KI) less than baseline

KI are marked in green.

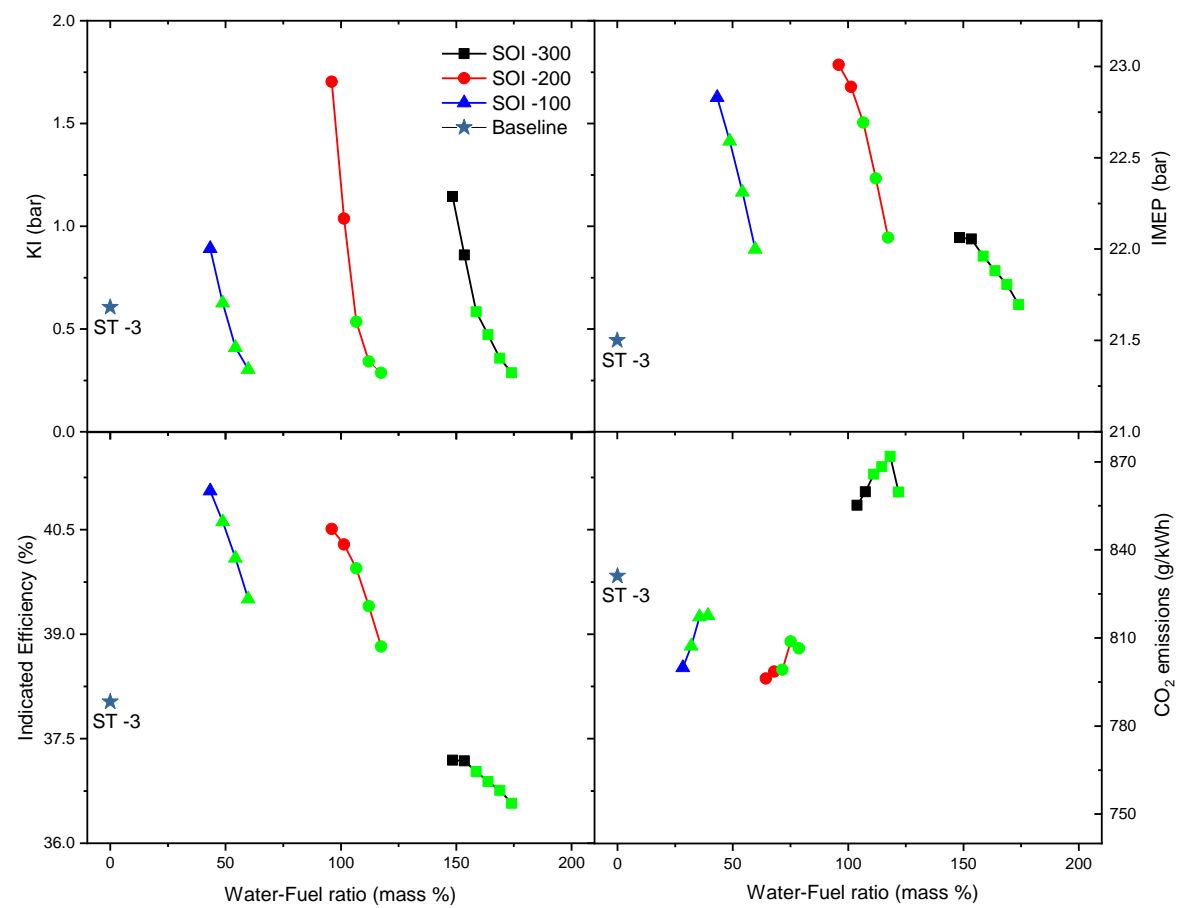

Figure 13: (a) Knock Intensity (bar), (b) IMEP (bar), (c) Indicated Efficiency (\%) and (d) $\mathrm{CO}_{2}$ emissions ( $\mathrm{g} / \mathrm{kWh}$ ) for in-cylinder water injection. Intake pressure was fixed at 1.80 bar. Four different start of injection are shown: -300 (black), -200 (red) and -100 (blue) CAD aTDC. The baseline values refer to operation without water injection (spark timing -3 CAD aTDC). Data-points with knock intensity (KI) less than baseline KI are marked in green.

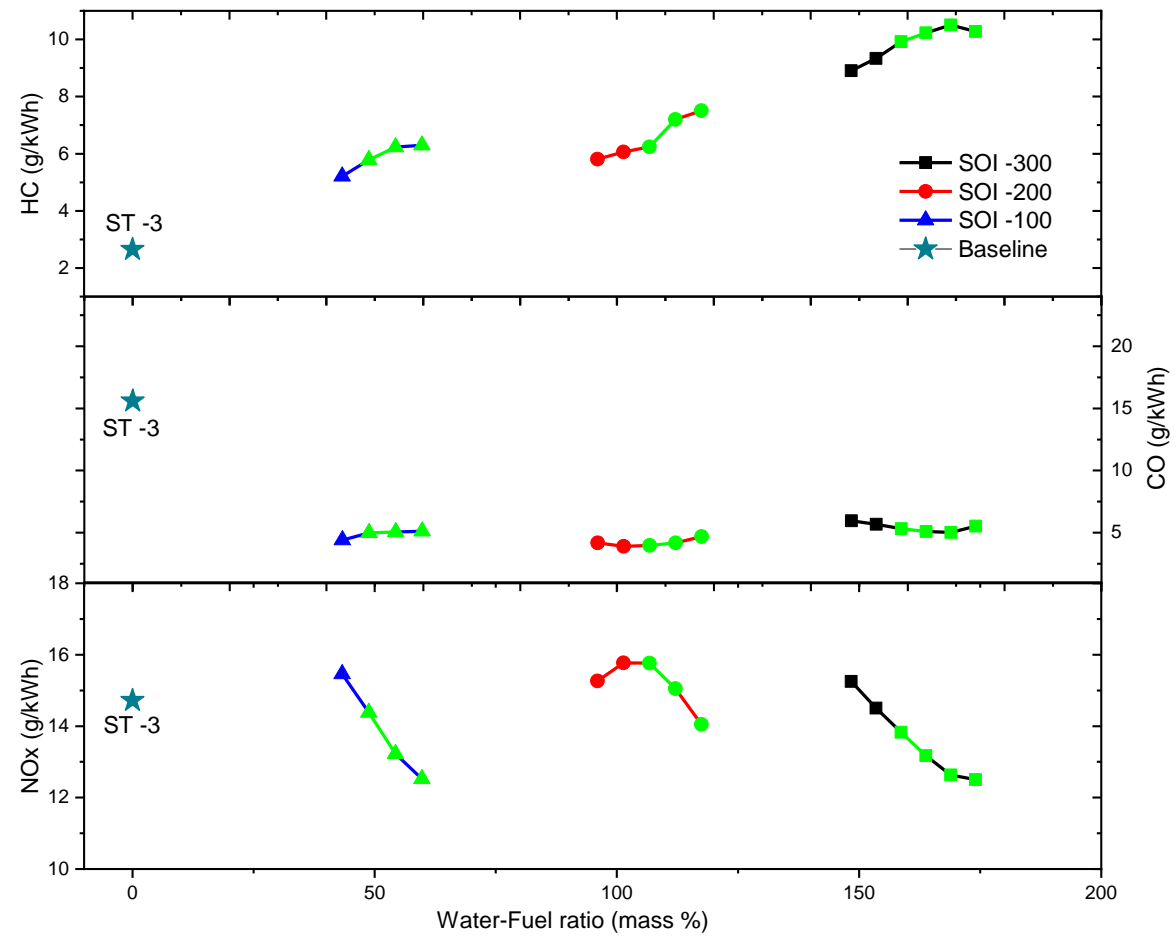


Figure 14: (a) Hydrocarbon emissions ( $\mathrm{g} / \mathrm{kWh}$ ), (b) Carbon Monoxide emissions ( $\mathrm{g} / \mathrm{kWh}$ ), and (c) Nitrogen Oxides ( $\mathrm{g} / \mathrm{kWh}$ ) for water injection via port. Intake pressure was fixed at 1.80 bar. Four different start of injection are shown: -300 (black), -200 (red) and -100 (blue) CAD aTDC. The baseline values refer to operation without water injection (spark timing -3 CAD aTDC). Data-points with knock intensity (KI) less than baseline KI are marked in green.

\subsubsection{The effect of water injected mass with varying air intake pressure:}

Although different water masses are required to suppress knock at each intake air pressure, a few water mass cases are common to intake air pressure 1.2, 1.4, and 1.6 bar cases (albeit resulting in different knock intensities). Such common water mass cases are compared in this section. Firstly, the IMEP achieved for each intake air pressure case is shown in figure 15. For low intake air pressure case of 1.22 bar, a relatively small water mass was enough to suppress the knock to a tolerable level. In contrast, at an intake air pressure of $1.6 \mathrm{bar}, 3.2 \mathrm{mg}$ water case was not recorded due to severe knock. All the observations are for a fixed spark timing of -18 CAD aTDC. With an increase in injected water mass, the IMEP generally decreases due to slower combustion.

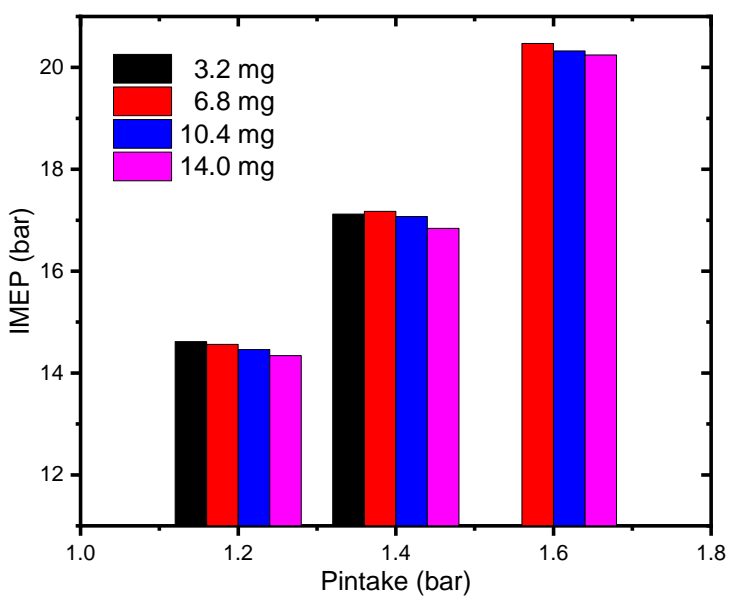

Figure 15: Effect of varying amounts of water injection on IMEP is shown for different intake air pressures. Generally, the IMEP tends to decrease with more water injected; this is driven by the retarded start of combustion and slower combustion with increasing water injection quantity.

Next, the knock intensity is shown for the same water mass and intake air pressure in figure 16 . It can be observed that a given water mass is less effective at suppressing knock as the intake pressure increases. This is expected as a knock is exacerbated with increasing intake pressure (or load), requiring a larger mass of water to achieve the same level of knock intensity. For the same intake air pressure, the KI decreases more at low water mass injected, and the reduction in KI decreases as the injected water mass increases.

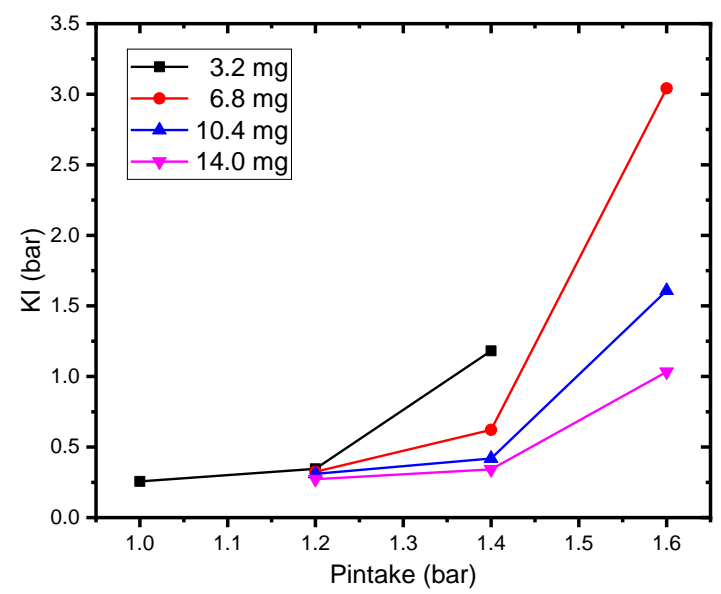

Figure 16: Effect of varying amounts of water injection on knock intensity is shown for different intake air pressures. The knock intensity reduces with more water injected. However, the extent of reduction decreases as the water injection quantity increases. 
The combustion phasing is shown as a function of intake air pressure and water mass injected in figure 17. The trend seen previously is consistent over varying intake air pressure. The mass fraction of water reduces as the intake pressure increases (more fuel-air mass is inducted for the same mass of water injected). Hence, the charge cooling effect and the effect on slowing down the combustion, is relatively lower at higher intake air pressure. This leads to a general advancement of the start of combustion and combustion phasing with increasing air intake pressure (and load). Moreover, at each intake air pressure case, the combustion phasing advance is consistent with increased injected water mass.

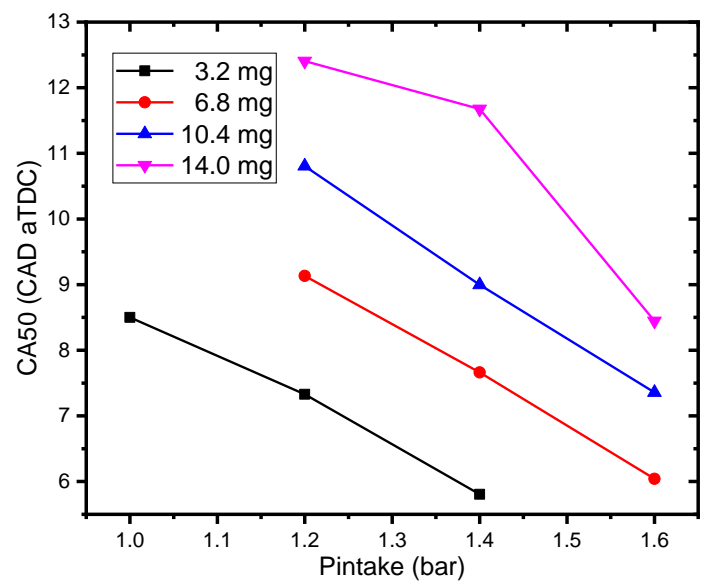

Figure 17: Effect of varying amounts of water injection on the start of combustion, combustion phasing, and duration of combustion is shown for different intake air pressures. With increasing water injection quantity, the start of combustion is retarded, but the value decreases as the intake air pressure increases. Similar observations are shown for combustion phasing and duration of combustion.

Figure 18 shows a typical pressure trace from a case of direct injection of water at -100 CAD aTDC and intake air pressure 1.07 bar. Charge cooling impacts the peak pressure reached at the end of the compression stroke (point ' $a$ ' in figure 18), leading to a lower (and later) peak pressure at the end of heat addition (point ' $b$ ' in figure 18). The decreasing (and retarding) peak pressure with water addition translates to a reduction in positive work extracted from the cycle (shown with a red arrow). However, a higher specific heat ratio of water leads to a crossover point after the main heat addition. This leads to a higher positive work in the power stroke with water injection (shown with a green arrow).

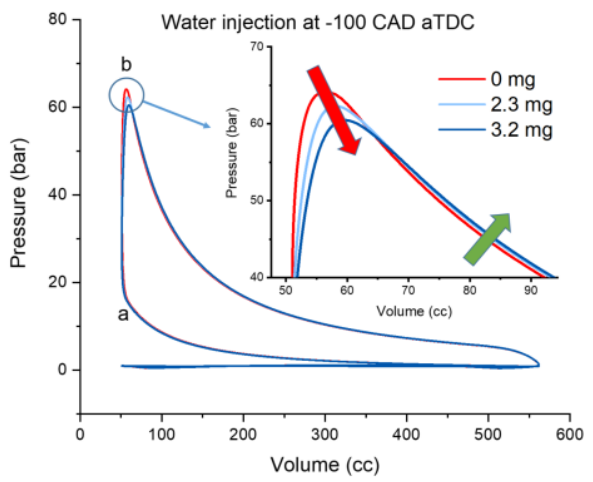

Figure 18: Pressure-Volume traces for direct injection of water at-100 CAD aTDC. Intake air pressure is set to 1.07 bar and varying mass of water is injected to achieve knock suppression. The pressure-volume near the top dead center are zoomed in and shown in inset of the figure.

Figure 19 shows a similar pressure-volume trace for intake air pressure $1.80 \mathrm{bar}$. The blue curve refers to the baseline case with a retarded spark timing of -3 CAD aTDC, resulting in lower IMEP (proportional to the area under the pressure-volume curve). With an advanced spark timing of -18 CAD aTDC, a higher area under the curve is achieved (higher IMEP). Moreover, a higher mass of water shall increase compression work, leading to a slight reduction in peak compression pressure with water addition. 


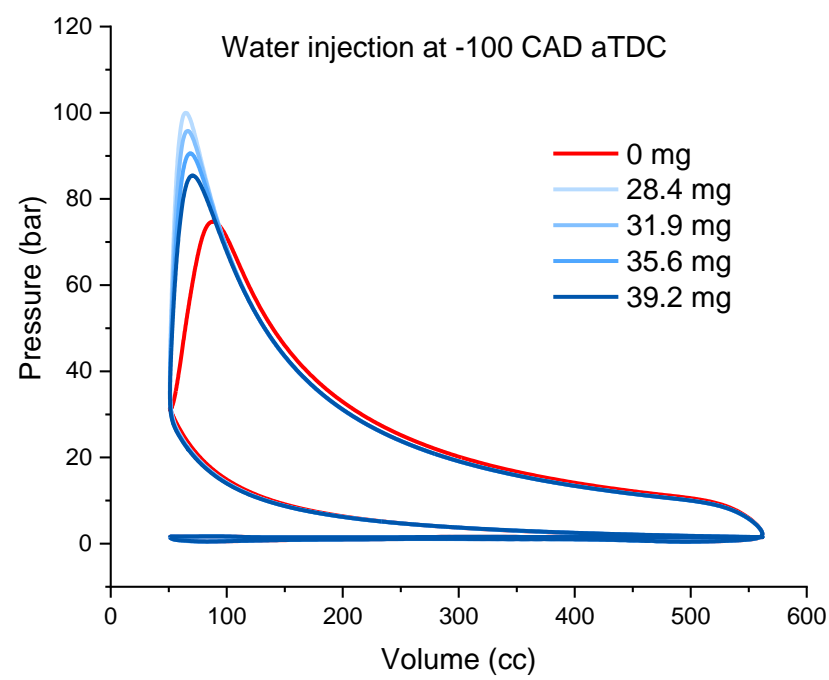

Figure 19: Pressure-Volume traces for direct injection of water at-100 CAD aTDC. Intake air pressure is set to 1.80 bar and varying mass of water is injected to achieve knock suppression. The knock limited case without water injection is operated at spark timing of -3 CAD aTDC, while the cases with water injection are operated at spark timing of -18 CAD aTDC.

417 Next, experiments were performed to assess the maximum brake torque timing for the intake air pressure cases considered above. For these experiments, SoI of water injection was fixed at -100 CAD aTDC (most effective SoI in the above cases), and spark timing was advanced until maximum brake torque was achieved. Simultaneously, water was injected to avoid knock occurrence as spark timing is advanced. Figure 20 shows the IMEP achieved at various intake air pressures and the water-fuel ratio required to achieve MBT. As seen in figure 17 before, water injection slows combustion duration. Hence, to maintain MBT timing at high load with large water mass injection, spark timing was advanced. Due to fixed SoI of water, MBT operation could not be reached at 1.80 bar intake air pressure (shown in red). Further addition of water increased cycle-to-cycle variation beyond the tolerable limit of $2 \%$. The inset shows the pressure traces of the five intake air pressure cases considered, with a red curve referring to 1.80 bar intake air pressure, where MBT timing was not reached. The high cycle-to-cycle variation can be seen in the pressure traces for 1.80 bar intake air pressure case, shown in the inset. The maximum water-fuel mass ratio required to suppress knock, when injecting at $-100 \mathrm{CAD}$ aTDC, was $\sim 60 \%$ in the previous cases (when spark timing was fixed at -18 CAD aTDC). In figure 19, nearly $80 \%$ of fuel mass (which corresponds to $67 \mathrm{mg} /$ cycle water) is injected over $52 \mathrm{CAD}$ from the start of injection, leaving a large mass unevaporated, inhibiting flame development, and increasing cycle-to-cycle variation.

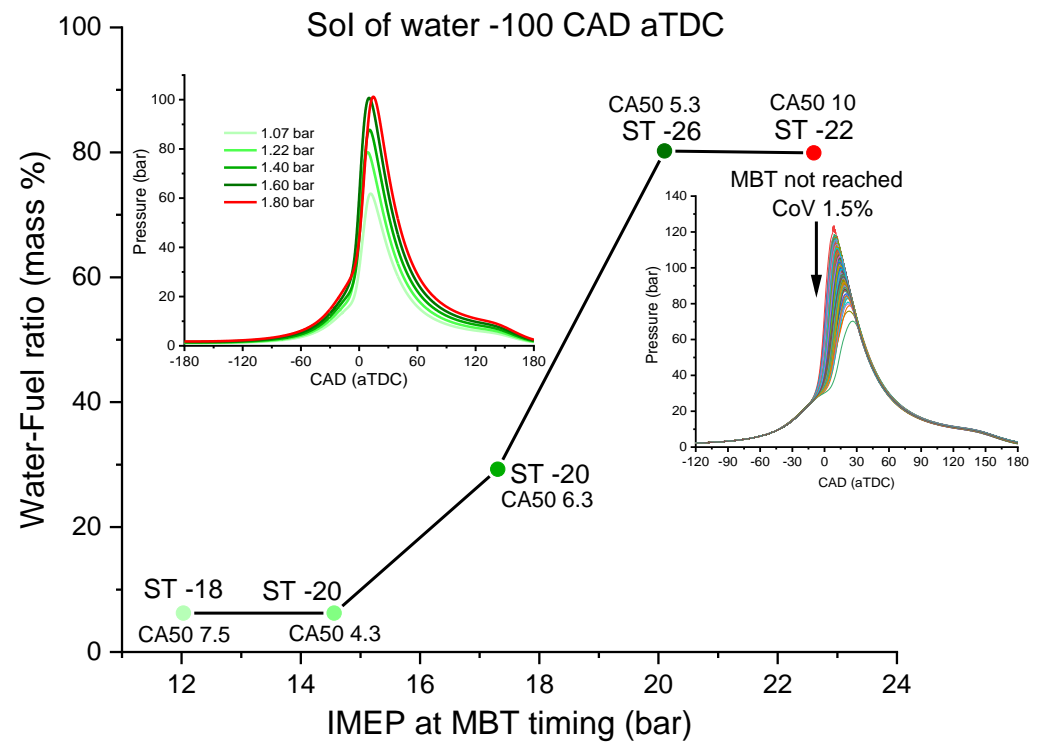

432 
Figure 20: MBT timings were achieved for the above-mentioned cases at SoI of water at-100 CAD aTDC. Greater water-fuel ratio was needed at increasing load and the spark timing was advanced further to maintain combustion phasing and MBT. Inset shows the Pressure-CAD diagram for the cases considered. For intake air pressure 1.8 bar, MBT timing could not be reached at maximum water injection quantity, due to high cycleto-cycle variation, as shown in inset figure.

Overall, water injection impacts engine operation in several ways. The increase in charge mass increases compression work, while an increase in burnt mixture's specific heat ratio increases expansion work. Charge cooling also results in lower peak compression temperature and pressures, allowing advanced spark timing, leading to higher IMEP. Increasing intake pressure exacerbates the knock problem, requiring a more water injection to achieve comparable spark timings. The charge cooling effect is best utilized by injecting water in a hot fuel-air mixture (closer to the top dead center) while also ensuring evaporation of all the injected water mass.

\subsubsection{Pre-ignition suppression using water injection}

In this section, two cases are shown to emphasize water injection's effect on avoiding engine damage. Figure 21 shows the in-cylinder pressure-CAD trace for intake air pressure of 1.6 bar. Figure 21a is a stoichiometric operation with fuel mass $58.5 \mathrm{mg} /$ cycle without water injection showing high knock intensity. Figure $21 \mathrm{~b}$ achieves maximum brake torque (MBT) timing with spark timing -26 CAD aTDC with water injection. An earlier spark timing is required due to slower combustion with water addition. A stoichiometric air-fuel ratio was maintained for MBT timing with fuel mass $60 \mathrm{mg} /$ cycle (due to slightly increased unburnt hydrocarbon emissions as seen earlier) and water mass of 48.2 $\mathrm{mg} / \mathrm{cycle}$ at SoI -100 CAD aTDC. Very high knock intensity can be observed in figure $21 \mathrm{a}$. Only a few cycles were recorded due to the deleterious effect of such high knocking cycles on engine health. We can observe knock-free operation in figure $21 \mathrm{~b}$ while still achieving a similar level of IMEP as the knocking case.
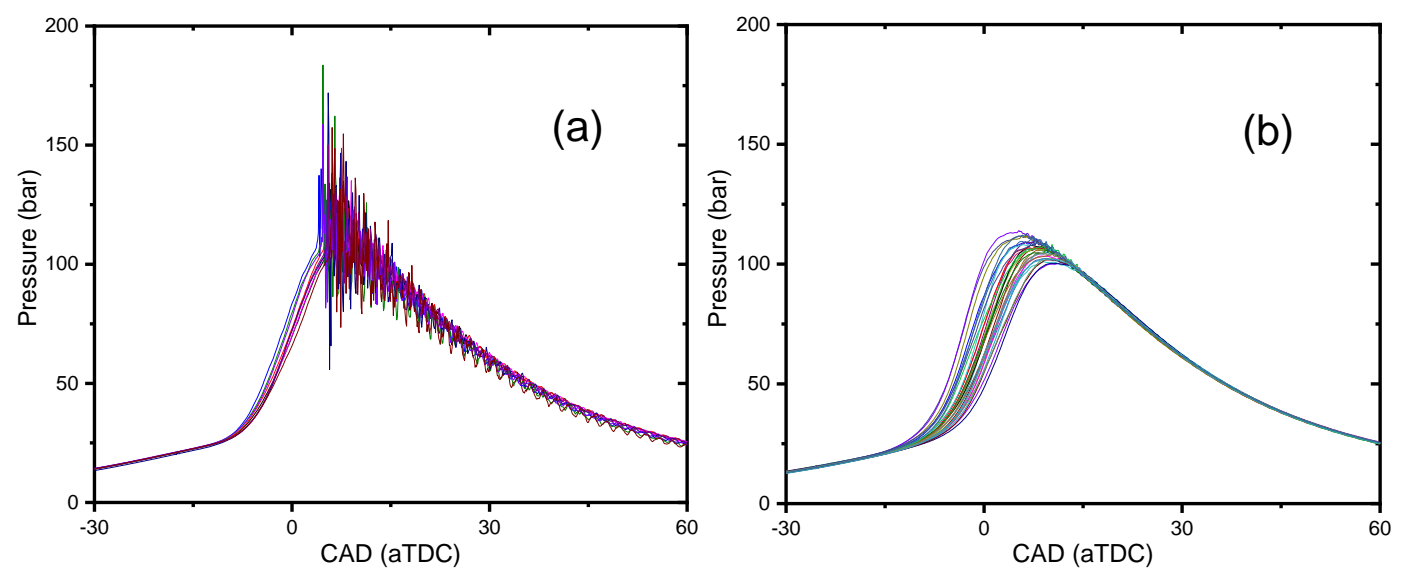

Figure 21: A typical case of pressure-CAD diagram is shown (a) without water injection (left) and (b) with water injection (right). The depicted observations are made for an intake air pressure of 1.60 bar. A huge reduction in knock intensity while maintaining the IMEP can be observed.

The experiments with direct water injection were done until intake pressure of 2.10 bar. At such high load operation, a spark timing of -18 CAD aTDC is impossible without inflicting permanent damage from a heavy knock. Moreover, when running the engine at air intake pressure of 2.10 bar, operating at knock limited spark timing is not risk-free. Stochastic pre-ignition events are frequent at such high load, when rogue particles (deposits or oil-fuel droplets) trigger the ignition of the charge before the spark timing. Figure 22a shows one such pre-ignition cycle when operating the engine with spark timing 0 CAD aTDC (knock-limited spark timing). The operation is stoichiometric, with 74 $\mathrm{mg} / \mathrm{cycle}$ fuel injected. Previous studies have shown that in-cylinder temperature near TDC is critical to triggering a pre-ignition event $[41,46,47]$. Figure 22b shows the operation with $43 \mathrm{mg} / \mathrm{cycle}$ water injection at SoI -100 CAD aTDC. Water injection reduces the mixture temperature near TDC while also reducing the chemical reactivity, both of which inhibit pre-ignition tendency. Apart from a knock and pre-ignition free operation, it provides higher IMEP and indicated efficiency (data provided in the appendix). This study was able to achieve IMEP $\sim 27$ bar with no preignition events. 

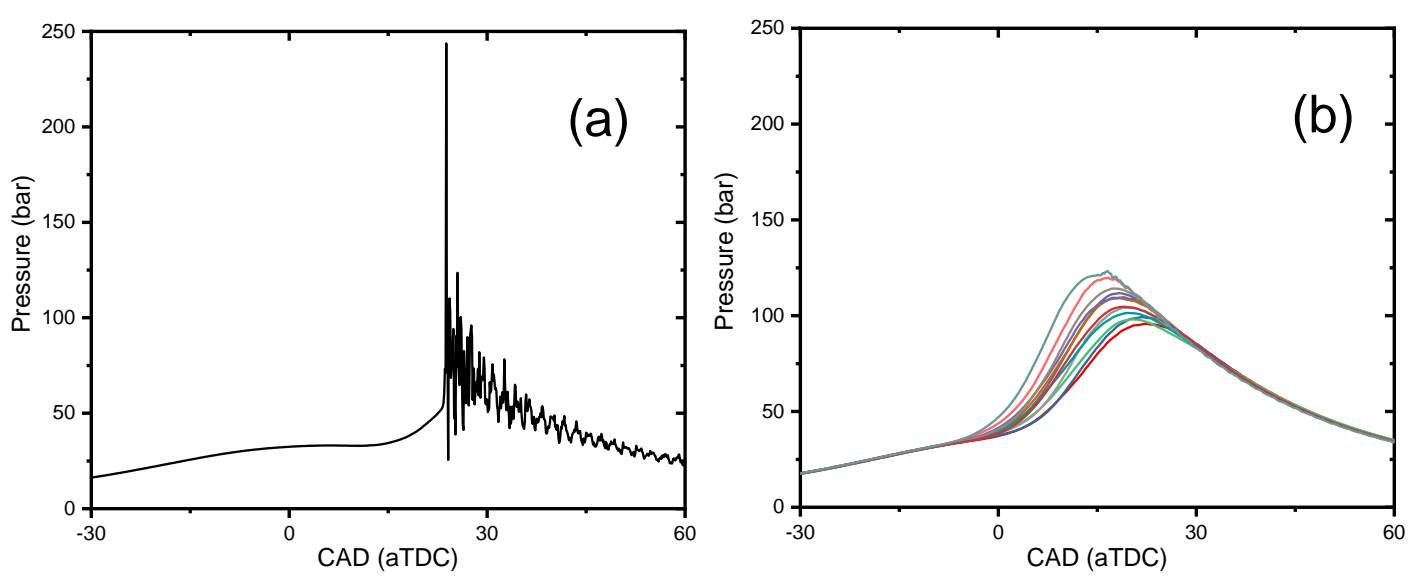

Figure 22: A typical case of a pressure-CAD diagram is shown for a pre-ignition case (left) observed at an intake air pressure of 2.10 bar. Apart from extremely reduced IMEP, very high knock intensity can be observed. The operation at the same intake pressure with water injection is also shown for comparison (right).

Water injection has been explored further, concerning its pre-ignition suppression tendency in a previous work [44]. Key findings relevant to the pre-ignition suppression by water injection are discussed here. Water was injected in intake stroke (SoI -300 and -200 CAD aTDC) when the intake valves were open, in compression stroke (-90 and -30 CAD aTDC), and late exhaust stroke (330 and 350 CAD aTDC), as shown in figure 23a. Injecting water in the intake stroke and compression stroke has been shown earlier in this work. Injecting in compression stroke led to a more significant charge cooling effect, leading to lower knock intensity in figures 10 and 13. Low in-cylinder temperature near the top dead center has been directly linked to lower pre-ignition tendency. Pre-ignition frequency with varying water injection quantity is shown in figure 23b. 45,000 cycles were recorded in three sets of 15,000 cycles each, and the pre-ignition count is shown in terms of \% (per 100 cycles). Intake stroke water injection (shown in blue) tremendously reduces the pre-ignition frequency. When injecting water early in compression stroke (-90 CAD aTDC), it proved to be the most effective strategy in our tests. However, injecting at -30 CAD aTDC was the least effective strategy. SoI -30 CAD aTDC provides little time for water to evaporate completely, thereby not utilizing the injected water's charge cooling potential. Water was also injected late in the exhaust stroke, which allowed isolating the trapped burned gas to be cooled/quenched before the next cycle begins. As it can be observed, the water injection occurs when the exhaust valves are nearly closed, while the intake valves are yet to open. In this way, the water injection does not actively cool the incoming charge, and the temperature at the top dead center does not decrease substantially (apart from the temperature reduction from the cooling of the residual gas content). The highlighted red points in figure $23 \mathrm{~b}$ show that the strategy is as effective as injecting in intake stroke in suppressing pre-ignition. The experiments confirm that particles in the residual gas potentially trigger pre-ignition events in the next cycle. Other additives, like alcohol, cannot be used to suppress pre-ignition in this strategy, as it will lead to post-combustion or high engine-out hydrocarbon emissions. Moreover, a conceptual framework may be proposed for pre-ignition with these experiments and observations made in [47]. 

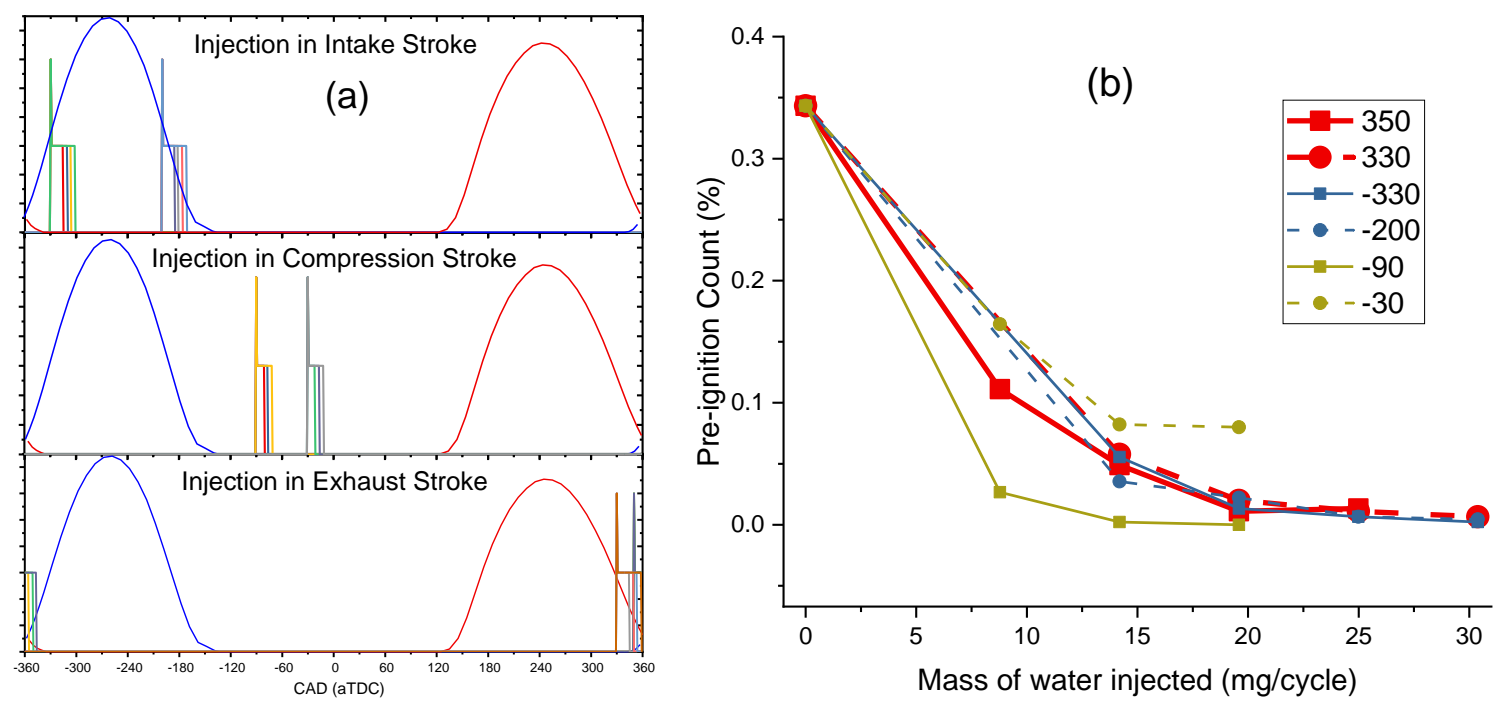

Figure 23: (a) Injection strategies employed for water injection. Six different SoI in intake, compression and exhaust stroke are employed. Intake (blue) and exhaust valve (red) lift is shown for reference. The spike is to show the SoI, while the width corresponds with the DoI of each case [49]. (b) Pre-ignition count for water injection at different start of injection timings (SoIs). Red points refer to injection in the late exhaust stroke, blue points refer to injection in the intake stroke and yellow points refer to injection in the compression stroke.

Liquid fuel interacts with oil-film on the liner surface. Diluted oil-fuel mixture droplets rest on the ring crevice until they are launched into the combustion chamber due to the piston movement near the top dead center. The cold droplets are heated (and possibly burned) during a normal combustion cycle. The burned gases are scavenged out of the engine in the exhaust stroke. However, residual gases and heavier (larger) particles may remain in the engine due to a nonideal scavenging process. These particles can trigger a pre-ignition event in a reactive atmosphere around it.

\subsection{Impact of water injection on suppressing reactivity via chemical pathways:}

The effect of water addition on suppressing chemical reactivity can be understood by isolating the ignition behavior at the same initial condition of temperature and pressure. Chemical kinetic simulations were conducted with a varying mass of water added to fuel-air mixtures. A surrogate fuel PRF95 (95\% v/v iso-octane and 5\% v/v $n$-heptane) was used as fuel and stoichiometric mixture was prescribed. A homogeneous batch reactor model was used, and the energy equation is solved for a fixed initial temperature and pressure condition. The results are shown for a range of initial temperature conditions: 600 to $1000 \mathrm{~K}$, with a step of $20 \mathrm{~K}$ and initial pressure 25 bar. The temperature range covers the low, intermediate, and high-temperature regions, which exhibit different reactivity. The simulations are done with water added to the fuel in the ratio of 0 to 1.5. Figure 24 shows the ignition delay time plotted against the inverse of temperature. Water injection barely affects the high-temperature reactivity, while noticeable difference in ignition delay times can be observed in the low and intermediate temperature region. The kinetics behind the low and hightemperature reactivity has been discussed in detail elsewhere [48]. In brief, in the case of long-chain paraffins (C4 and above), oxygen addition to the fuel radical and subsequent intramolecular isomerization leads to the formation of ketohydroperoxides. These could add further oxygen or decompose to form $\mathrm{OH}$ radicals, leading to low-temperature heat release. At increased temperature, this chain branching pathway is inhibited in favor of chain propagation (cyclic ether formation) and chain termination (formation of alkenes and $\mathrm{HO}_{2}$ ) reactions. These competing reactions yield lower reactivity in the intermediate temperature region, known as the negative temperature coefficient (NTC) region, where reactivity decreases with increasing temperature until high-temperature reactivity kicks in and conventional Arrhenius type reactivity is observed. The $\mathrm{HO}_{2}$ radical abstracts $\mathrm{H}$ from the fuel and forms $\mathrm{H}_{2} \mathrm{O}_{2}$ radical in the intermediate temperature. Subsequently, the decomposition of $\mathrm{H}_{2} \mathrm{O}_{2}$ into $\mathrm{OH}$ leads to high-temperature reactions. Reduced reactivity in the low and intermediate temperature with water addition has been observed by other researchers [38]. 
Previous works have shown that RON and MON values correspond with ignition delay times in the NTC region [49, 50]. The corresponding initial temperatures are marked in figure 24 with dashed lines. It can be observed that ignition delay is improved further at RON condition than MON condition.

Octane sensitivity of a fuel is the difference between RON and MON ( $\mathrm{S}=\mathrm{RON}-\mathrm{MON}$ ), and a more pronounced NTC behavior is associated with low octane sensitivity. Figure 24 hints at an increase in octane sensitivity with water addition. This aspect is further investigated by modeling the state of end-gas ahead of the flame front in RON/MON experiments. The methodology used is similar to [51]. Instead of a constant pressure, a pressure-time history is imposed, based on experimental RON/MON pressure data. Initial condition of $502 \mathrm{~K}$ and $3.06 \mathrm{~atm}$ for RON and 501 $\mathrm{K}$ and $2.07 \mathrm{~atm}$ for MON are initialized. Beyond the initial values, pressure profile are given as per experimental pressure traces from [51]. Figure 25 shows the heat release rates for (a) RON and (b) MON-like case. RON-like case exhibits low temperature heat release, which is suppressed with water addition, leading to a delayed auto-ignition ( 3.5 CAD). For the MON-like case, the impact of water addition is negligible. Water injection is compared against PRF95 in both cases, which has zero sensitivity. Hence, addition of water increases octane sensitivity of the blend.

Like the one used in the current work, modern turbocharged engines operate at beyond-RON conditions at high loads, where a high RON and octane sensitivity are desired for improved knock suppression. To map the engine operating conditions used in the current study, they are plotted on a pressure-temperature diagram in figure 26. RON and MON trajectories are also provided for reference. RON tests are conducted at $600 \mathrm{rpm}$, giving enough residence time for low temperature reactions to occur. Modeling the end-gas in a RON-like case, shows a deviation from adiabatic-type compression, due to temperature increase from low temperature reactions. This is marked by a dot in the RON-like trajectory. Such reactions are not observed in other cases. MON-like trajectory is at relatively high temperature, while the current experiments are conducted at $2000 \mathrm{rpm}$ resulting in low residence time for the end-gas to observe any low temperature reactions. Due to low intake air temperature and high intake pressure operating conditions, these trajectories are beyond-RON in figure 26. The change in ignition delay time with water addition is also shown in a colormap in figure 26. An extreme case of $150 \%$ water-fuel ratio is used, and the relative change in ignition delay time with water addition with respect to ignition delay time of PRF95 is plotted. The largest benefits are realized in intermediate temperature range for all cases. Interestingly, the benefit of adding water is lower at intake air pressure 2.10 bar. It can also be observed that same water-fuel ratio will impact auto-ignition differently, depending on the trajectory followed. At high temperature conditions, negative values suggest that ignition delay time decreases with water addition. This can be attributed to availability of $\mathrm{OH}$ radical from dissociation of water at high temperature. This methodology allows extrapolation of current results into other realms of speed-load-intake temperature and pressure. From a chemical-reactivity perspective alone, water injection will yield maximum benefit at low speeds, high intake pressure conditions (typical of modern turbocharged engines).

These simulations consider a homogeneous mixture of fuel-air-water in gaseous form. Hence, the observations point towards the knock suppression tendency of water from the chemical pathway alone. The physical properties of latent heat of vaporization and specific heat have been discussed earlier and it was observed that injecting water in hightemperature stream helps in realizing latent heat effect better (injecting in hot-intake air or injecting late in compression stroke). Overall, considering the engine operating conditions used in the current study, knock is avoided by both physical and chemical reactivity suppression.

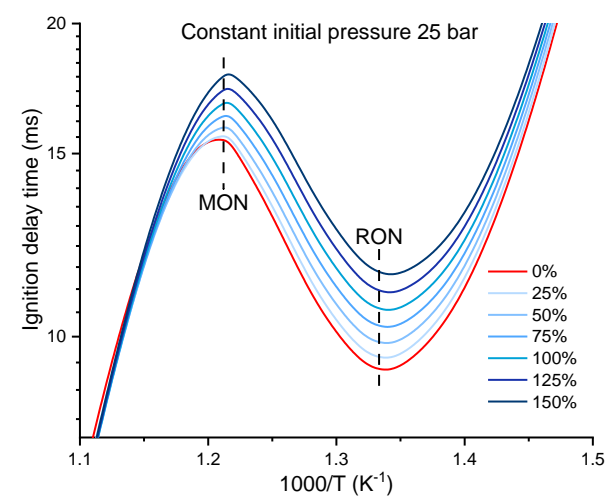


Figure 24: Ignition delay times calculated using homogeneous batch reactor simulations. Water is 'added' to the premixed air-fuel quantity in
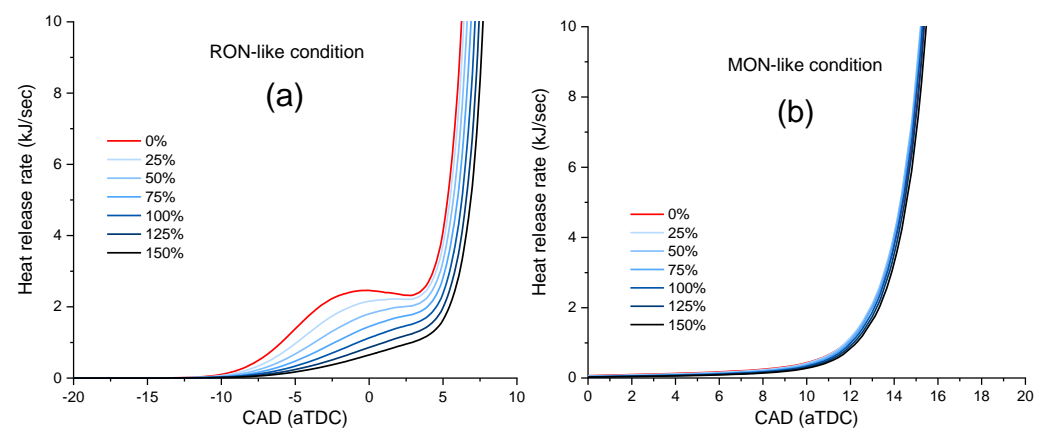

Figure 25: History of heat release rates of RON/MON-like simulations for varying ratio of water-fuel mass ranging from 0 to $150 \%$. Low temperature heat release is suppressed in RON-like condition with addition of water, while no significant change is observed in MON-like condition.

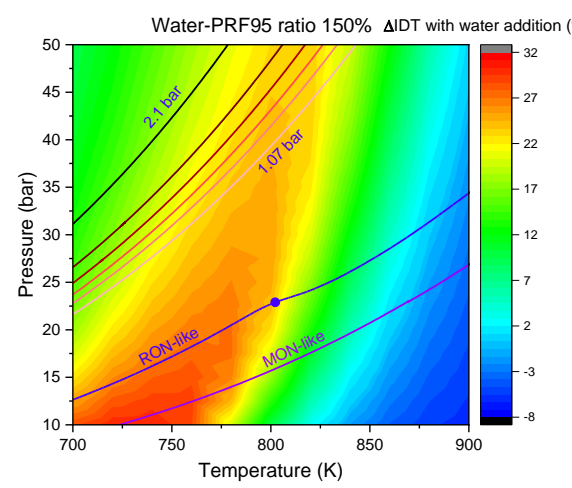

Figure 26: Temperature-pressure trajectories for the operating conditions used in the current study are shown. RON and MON end-gas trajectories are also shown for reference. RON-like condition deviates from the adiabatic compression curve when low temperature heat is released at the marked point (blue dot), while no such deviations are observed for the remaining trajectories. The temperature-pressure trajectories are overlaid on relative change in ignition delay with addition of $150 \%$ water in PRF95.

4. Conclusions:

An extensive experimental campaign was carried out to investigate water injection effectiveness through port and direct injection route. Several key conclusions can be made concerning the effectiveness of water injection at suppressing knock.

1. Water injection was first attempted with the port injector. The injection was made during an intake valve open duration to maximize the charge cooling effect. Although efficiency improvements up to $3.5 \%$-points were observed, the reduced volumetric efficiency led to reduced IMEP at high load operations. NOx and CO emissions are reduced at all loads, while HC emissions increased at high load (IMEP > 16 bar).

Operation beyond 17 bar IMEP, while maintaining the MBT spark timing, was not possible with port injection. Direct Naturally, water mass required for knock suppression increased with increasing intake air pressure.

2. Water is highly effective at suppressing knock at all intake air pressures. Injecting a small amount of water reduced knock drastically, and there is diminishing returns with further water injected mass. The improved effectiveness at increased intake pressure is explained by the suppressing chemical reactivity in the NTC region.

3. $\mathrm{HC}$ emissions increased, while $\mathrm{NOx}$ and $\mathrm{CO}$ emissions were reduced at all operating conditions for direct water injection. 
4. Improved effectiveness from injecting in late compression stroke was limited by the time required for complete water evaporation. In this regard, the optimized injection timing was observed to retard as the load increased.

5. Water injection increased the duration of combustion and ignition delay time, leading to a reduction in IMEP, indicated efficiency and $\mathrm{CO}_{2}$ emissions for a fixed spark timing.

6. Water injection allowed pre-ignition free operation at high engine loads up to $27 \mathrm{bar}$. Water injection in the exhaust stroke suppressed pre-ignition, confirming residual gas content's role in triggering pre-ignition.

7. Considering only the chemical effect, addition of water increases octane sensitivity and the knock suppression is best realized at low-speed, high intake air pressure conditions.

Overall, this study shows the benefits of using water injection in a spark-ignited engine. This study realized efficiency gains up to $4 \%$-points and $\mathrm{CO}_{2}$ reductions up to $40 \mathrm{~g} / \mathrm{kWh}$. Moreover, all the experiments were performed with the stoichiometric operation, ensuring the highest efficiency of the three-way catalyst, even at IMEP over 27 bar. Water injection pushes the envelope of efficiency improvement opportunities in spark-ignited engines. With the introduction of real-world driving emissions cycles, stoichiometric operation at high load points is becoming a bottleneck to complying with emission norms. As seen in this study, water injection helps dramatically in this regard. The question of the source of water is not under the scope of the current study. However, it can be noticed that water injection was required only at knock-limited conditions, which form a minor fraction of the total driving cycle, which points to a low water requirement in daily usage. Water can be filled in another tank or even supplied from condensation in the engine exhaust or the air conditioning unit [52-54]. In the brief tests performed, no issues were observed with the injector or fuel line, but water's corrosive nature is well known and may need further studies before successful implementation can be made into commercial vehicles [55]. The work prospects include computational studies focused on mixing and evaporation of the water injection explaining the observations made in the current work.

\section{Acknowledgment}

This work was conducted with the help of several people. Adrian Ichim helped in setting up the engine and solving issues related to the engine. iAV provided a new module to run two separate pumps simultaneously that allowed direct injection of two fluids in the cylinder. The authors would like to thank Saudi Aramco for funding the project under the aegis of FuelCom II.

Nomenclature

\begin{tabular}{|c|c|c|c|}
\hline CAD & Crank Angle Degree & CA50 & $\begin{array}{l}\text { Crank angle degree for } 50 \% \text { mass fraction } \\
\text { burned }\end{array}$ \\
\hline aTDC & After Top Dead Center & CA90 & $\begin{array}{l}\text { Crank angle degree for } 90 \% \text { mass fraction } \\
\text { burned }\end{array}$ \\
\hline bTDC & Before Top Dead Center & DI & Direct Injection \\
\hline KI & Knock intensity & Pmax & Maximum Pressure \\
\hline IMEP & Indicated Mean Effective Pressure & $\mathrm{CO}_{2}$ & Carbon Dioxide \\
\hline $\mathrm{CoV}$ & Coefficient of variation & SOC & Start of Combustion \\
\hline ST & Spark Timing & DOC & Duration of Combustion \\
\hline Pin & Intake Pressure & $\mathrm{HC}$ & Hydrocarbon \\
\hline SOI & Start of Injection & $\mathrm{CO}$ & Carbon Mono oxide \\
\hline CA05 & $\begin{array}{l}\text { Crank angle degree for } 5 \% \text { mass fraction } \\
\text { burned }\end{array}$ & $\mathrm{NO}_{\mathrm{x}}$ & Nitric oxides \\
\hline CA10 & $\begin{array}{l}\text { Crank angle degree for } 10 \% \text { mass fraction } \\
\text { burned }\end{array}$ & SOI & Start of Injection \\
\hline $\mathrm{g} / \mathrm{kWh}$ & Grams per kilo Watt-hour & DOI & Duration of Injection \\
\hline
\end{tabular}

\section{References}

1. Tauzia, X., A. Maiboom, and S.R. Shah, Experimental study of inlet manifold water injection on combustion and emissions of an automotive direct injection diesel engine. Energy, 2010. 35(9): p. 3628-3639. 
2. Maiboom, A. and X. Tauzia, NOx and PM emissions reduction on an automotive HSDI Diesel engine with water-in-diesel emulsion and EGR: An experimental study. Fuel, 2011. 90(11): p. 3179-3192.

3. Bedford, F., et al., Effects of direct water injection on DI diesel engine combustion. 2000, SAE Technical Paper.

4. Tesfa, B., et al., Water injection effects on the performance and emission characteristics of a CI engine operating with biodiesel. Renewable Energy, 2012. 37(1): p. 333-344.

5. Abu-Zaid, M., Performance of single cylinder, direct injection diesel engine using water fuel emulsions. Energy conversion and Management, 2004. 45(5): p. 697-705.

6. Kohketsu, S., et al., Reduction of exhaust emission with new water injection system in a Diesel engine. SAE transactions, 1996: p. 74-81.

7. Samec, Niko, Robert W. Dibble, Jyh Y. Chen, and Andrej Pagon. Reduction of NOx and soot emission by water injection during combustion in a diesel engine. No. 2000-05-0079. SAE Technical Paper, 2000.

8. Kaneko, N., et al., Expansion of the operating range with in-cylinder water injection in a premixed charge compression ignition engine. SAE Transactions, 2002: p. 2309-2315.

9. Iwashiro, Yuki, Tadashi Tsurushima, Yoshiaki Nishijima, Yasuo Asaumi, and Yuzo Aoyagi. Fuel consumption improvement and operation range expansion in HCCI by direct water injection. No. 2002-01-0105. SAE Technical Paper, 2002.

10. Clerk, Dugald. "Cylinder actions in gas and gasoline engines." SAE Transactions (1921): 33-92.

11. Hopkinson, B., A new method of cooling gas-engines. Proceedings of the Institution of Mechanical Engineers, 1913. 85(1): p. 679-715.

12. Miller, C.D., End-zone water injection as a means of suppressing knock in a spark-ignition engine. 1944.

13. Fritz, Nallinger. "Internal combustion engine." U.S. Patent 2,221,405, issued November 12, 1940.

14. Kuhring, M., Water and Water-Alcohol Injection in a Supercharged Jaguar Aircraft Engine. Canadian Journal of Research, 1938. 16(8): p. 149-176.

15. Rowe, M. and G. Ladd, Water injection for aircraft engines. 1946, SAE Technical Paper.

16. Nicholls, J., I.A. El-Messiri, and H. Newhall, Inlet manifold water injection for control of nitrogen oxidestheory and experiment. SAE Transactions, 1969: p. 167-176.

17. Modak, A., and Laurence Stephen Caretto. Engine cooling by direct injection of cooling water. No. 700887. SAE Technical Paper, 1970.

18. Weatherford, W. D., and R. D. Quillian. Total cooling of piston engines by direct water injection. No. 700886. SAE Technical Paper, 1970.

19. Lestz, Samuel S., Wolfgang E. Meyer, and C. M. Colony. "Emissions from a direct-cylinder water-injected spark-ignition engine." SAE Transactions (1972): 392-398.

20. Peters, B.D. and R.F. Stebar, Water-gasoline fuels-their effect on spark ignition engine emissions and performance. SAE Transactions, 1976: p. 1832-1853.

21. Harrington, J., Water Addition to Gasoline-Effect on Combustion, Emissions, Performance, and Knock. SAE transactions, 1982: p. 1226-1251.

22. Berni, Fabio, Sebastiano Breda, Alessandro D'Adamo, Stefano Fontanesi, and Giuseppe Cantore. Numerical investigation on the effects of water/methanol injection as knock suppressor to increase the fuel efficiency of a highly downsized GDI engine. No. 2015-24-2499. SAE Technical Paper, 2015. 
23. Hoppe, F., et al., Evaluation of the Potential of Water Injection for Gasoline Engines. SAE International Journal of Engines, 2017. 10(2017-24-0149): p. 2500-2512.

24. Hoppe, F., et al., Water injection for gasoline engines: Potentials, challenges, and solutions. International Journal of Engine Research, 2016. 17(1): p. 86-96.

25. Battistoni, Michele, Carlo N. Grimaldi, Valentino Cruccolini, Gabriele Discepoli, and Matteo De Cesare. Assessment of port water injection strategies to control knock in a GDI engine through multi-cycle CFD simulations. No. 2017-24-0034. SAE Technical Paper, 2017.28.

26. Worm, J., et al., Water injection as an enabler for increased efficiency at high-load in a direct injected, boosted, SI engine. SAE International Journal of Engines, 2017. 10(3): p. 951-958.

27. Falfari, S., et al., Basics on Water Injection Process for Gasoline Engines. Energy Procedia, 2018. 148: p. 5057.

28. Rohit, Achint, Sridev Satpathy, Jeongyong Choi, John Hoard, Gopichandra Surnilla, and Mohannad Hakeem. Literature survey of water injection benefits on boosted spark ignited engines. No. 2017-01-0658. SAE Technical Paper, 2017.

29. Brusca, S., and R. Lanzafame. Water Injection in IC-SI Engines to Control Detonation and to Reduce Pollutant Emissions. No. 2003-01-1912. SAE Technical Paper, 2003.

30. Lanzafame, Raymond. Water injection effects in a single-cylinder CFR engine. No. 1999-01-0568. SAE Technical Paper, 1999.

31. Hermann, I., et al. Water Injection for Gasoline Engines-Quo Vadis? in International Conference on Knocking in Gasoline Engines. 2017. Springer.

32. Tsao, K. C., C. L. Wang, and E. M. Miller. Performance of gasoline-water fuel in a modified SI engine. No. 841399. SAE Technical Paper, 1984.

33. Hunger, M., et al. Potential of direct water injection to reduce knocking and increase the efficiency of gasoline engines. in International Conference on Knocking in Gasoline Engines. 2017. Springer.

34. Fu, Le-zhong, Zhijun Wu, Liguang Li, and Xiao Yu. Effect of Water Injection Temperature on Characteristics of Combustion and Emissions for Internal Combustion Rankine Cycle Engine. No. 2014-01-2600. SAE Technical Paper, 2014.

35. Fu, L., et al., Experimental investigation of combustion and emission characteristics for internal combustion rankine cycle engine under different water injection laws. Energy Procedia, 2015. 66: p. 89-92.

36. Heinrich, C., et al. Gasoline Water Direct Injection (GWDI) as a Key Feature for Future Gasoline Engines. in International Conference on Knocking in Gasoline Engines. 2017. Springer.

37. Thewes, M., et al., Water injection for gasoline combustion systems. MTZ worldwide, 2015. 76(2): p. 10-15.

38. Netzer, C., et al., Numerical analysis of the impact of water injection on combustion and thermodynamics in a gasoline engine using detailed chemistry. SAE International Journal of Engines, 2018. 11(2018-01-0200): p. 1151-1166.

39. Vacca, Antonino, Michael Bargende, Marco Chiodi, Tim Franken, Corinna Netzer, Maike Sophie Gern, Malte Kauf, and André Casal Kulzer. Analysis of Water Injection Strategies to Exploit the Thermodynamic Effects of Water in Gasoline Engines by Means of a 3D-CFD Virtual Test Bench. No. 2019-24-0102. SAE Technical Paper, 2019.

40. Cavina, N., et al., Investigation of water injection effects on combustion characteristics of a gdi tc engine. SAE International Journal of Engines, 2017. 10(4): p. 2209-2218. 
41. Singh, Eshan, Mohammed Jaasim Mubarak Ali, Adrian Ichim, Kai Morganti, and Robert Dibble. Effect of mixture formation and injection strategies on stochastic pre-ignition. No. 2018-01-1678. SAE Technical Paper, 2018.

42. Cho, Seokwon, Namho Kim, Jongwon Chung, and Kyoungdoug Min. The effect of ethanol injection strategy on knock suppression of the gasoline/ethanol dual fuel combustion in a spark-ignited engine. No. 2015-01-0764. SAE Technical Paper, 2015.

43. Wang, J.-K., et al. Reduction of nitric oxide emission from a SI engine by water injection at the intake runner. in ASME 2009 International Mechanical Engineering Congress and Exposition. 2009. American Society of Mechanical Engineers.

44. Singh, Eshan, Ponnya Hlaing, Hao Shi, and Robert Dibble. Effect of Different Fluids on Injection Strategies to Suppress Pre-Ignition. No. 2019-01-0257. SAE Technical Paper, 2019.

45. Zhu, S., et al., A review of water injection applied on the internal combustion engine. Energy conversion and management, 2019. 184: p. 139-158.

46. Singh, Eshan, Kai Morganti, and Robert Dibble. "Dual-fuel operation of gasoline and natural gas in a turbocharged engine." Fuel 237 (2019): 694-706.

47. Singh, Eshan, and Robert Dibble. Mechanism Triggering Pre-Ignition in a Turbo-Charged Engine. No. 201901-0255. SAE Technical Paper, 2019.

48. Sarathy, S. Mani, Goutham Kukkadapu, Marco Mehl, Tamour Javed, Ahfaz Ahmed, Nimal Naser, Aniket Tekawade et al. "Compositional effects on the ignition of FACE gasolines." Combustion and Flame 169 (2016): 171-193.

49. Singh, Eshan, Jihad Badra, Marco Mehl, and S. Mani Sarathy. "Chemical kinetic insights into the octane number and octane sensitivity of gasoline surrogate mixtures." Energy \& Fuels 31, no. 2 (2017): 1945-1960.

50. Singh, Eshan, Efstathios-Al Tingas, Dimitris Goussis, Hong G. Im, and S. Mani Sarathy. "Chemical ignition characteristics of ethanol blending with primary reference fuels." Energy \& Fuels 33, no. 10 (2019): 1018510196.

51. Kim, Doohyun, Charles K. Westbrook, and Angela Violi. "Two-stage ignition behavior and octane sensitivity of toluene reference fuels as gasoline surrogate." Combustion and Flame 210 (2019): 100-113.

52. Vetrovec, Jan. "Internal combustion engine/water source system." U.S. Patent 7,302,795, issued December 4, 2007.

53. Budininkas, Pranas, and Philip A. Saigh. "Apparatus and method of recovering water from engine exhaust gases." U.S. Patent 4,656,831, issued April 14, 1987.

54. Jagtoyen, Marit, and Geoffrey M. Kimber. "Apparatus and method for the recovery and purification of water from the exhaust gases of internal combustion engines." U.S. Patent 6,581,375, issued June 24, 2003.

55. Chen, Y., K. Sridharan, and T. Allen, Corrosion behavior of ferritic-martensitic steel T91 in supercritical water. Corrosion Science, 2006. 48(9): p. 2843-2854. 